\title{
A comparison of the regional Arctic System Reanalysis and the global ERA-Interim Reanalysis for the Arctic ${ }^{\dagger}$
}

\author{
David H. Bromwich, ${ }^{\mathrm{a}, \mathrm{b} *}$ Aaron B. Wilson, ${ }^{\mathrm{a}}$ Le-Sheng Bai, ${ }^{\mathrm{b}}$ George W. K. Moore ${ }^{\mathrm{c}}$ and Peter Bauer ${ }^{\mathrm{d}}$ \\ ${ }^{a}$ Polar Meteorology Group, Byrd Polar and Climate Research Center, The Ohio State University, Columbus, USA \\ ${ }^{\mathrm{b}}$ Atmospheric Sciences Program, Department of Geography, The Ohio State University, Columbus, USA \\ ${ }^{\mathrm{c}}$ Department of Physics, University of Toronto, Ontario, Canada \\ ${ }^{\mathrm{d}}$ European Centre for Medium-Range Weather Forecasts, Reading, UK
}

${ }^{\star}$ Correspondence to: D. H. Bromwich, Byrd Polar and Climate Research Center, 1090 Carmack Road, Columbus, Ohio, USA.

E-mail: bromwich.1@osu.edu

\begin{abstract}
The Arctic System Reanalysis version 1 (ASRv1), a high-resolution regional assimilation of model output, observations and satellite data across the mid- and high latitudes of the Northern Hemisphere, and the global European Centre for Medium Range Forecasting Interim Reanalysis (ERAI) are compared with atmospheric observations for the period December 2006 to November 2007. Results throughout the troposphere show observations to be well assimilated in the ASRv1, as monthly and annual near-surface (upper-level) temperature, dew-point (relative humidity), pressure (geopotential height) and wind-speed biases compared with surface stations and radiosondes are very small. These results are similar to the ERAI, although wind-speed biases are significantly smaller in the ASRv1. Despite the ASRv1's use of a 3D-variational (Var) assimilation compared with the ERAI's 4D-Var, similar results suggest that a regional approach with higher-resolution terrain and a detailed land-surface description forced by a global reanalysis may improve the assimilation of observations and help offset temporal information lost by the 3D-Var compared with the 4D-Var. However, the ASRv1 forecast field results compared with the ERAI are mixed. The ASRv1 and ERAI show negative precipitation biases during cool months compared with gauge observations, and too much precipitation falls in the ASRv1 during summer in the midlatitudes. Stations north of $60^{\circ} \mathrm{N}$ demonstrate smaller precipitation biases in the ASRv1 than the ERAI except during the summer, when the ASRv1 is very dry. Short-wave radiation compared with observations is much too large in the ASRv1, and both reanalyses show long-wave radiation deficits during most months. These results point to inadequacies in model physics in the ASRv1 (e.g. convective and radiation schemes) that will continue to be refined in subsequent versions of the ASR.
\end{abstract}

Key Words: Arctic System Reanalysis; ERA-Interim; 3D-Var; WRFDA; Polar WRF

Received 21 March 2014; Revised 12 January 2015; Accepted 28 January 2015; Published online in Wiley Online Library

\section{Introduction}

Reanalyses provide a rich data resource that may be used to monitor climate variability and change, as they merge sparse and heterogeneous observations into a modelling framework to create a coherent, homogeneous, and comprehensive record of the atmospheric state through time. Early generation reanalyses were characterized by suboptimal sea-surface temperature (SST) and sea-ice concentration (SIC) fields, underdeveloped bias corrections for radiosonde and satellite observations, and coarse horizontal and vertical resolutions (Bengtsson et al., 2007). In order to better resolve important atmospheric processes in the troposphere and stratosphere, advances in numerical weather

${ }^{\dagger}$ Contribution 1452 of the Byrd Polar and Climate Research Center. prediction models, data assimilation methods and observing networks have led to a rapid development of a new suite of global reanalyses, including the European Centre for Medium-Range Weather Forecasts (ECMWF) Interim Re-Analysis (ERA-Interim, herein ERAI) (Dee et al., 2011), the National Aeronautics and Space Administration Modern-Era Retrospective Analysis for Research and Applications (MERRA) (Rienecker et al., 2011), and the coupled global atmosphere-ocean-land surface-cryosphere National Centers for Environmental Prediction (NCEP) Climate Forecast System Reanalysis (CFSR) (Saha et al., 2010). The latest effort toward a fully coupled and consistent climate reanalysis is currently underway at the ECMWF (Dee et al., 2014).

Although downscaling issues remain, regional models and reanalyses benefit from using global reanalyses as lateral boundary conditions (Wang et al., 2004; Laprise, 2008; McGregor, 2013; Hong and Kanamitsu, 2014). The large-scale atmospheric 
circulation generated by the global reanalyses may be downscaled to capture finer-scale features on the higher-resolution regional terrain. Additional obstacles in the creation of reanalyses include the need for consistent observational quality control, bias (drift) corrections and the optimization of assimilated observations. The last is also tied closely to regional and mesoscale processes that occur on scales poorly represented by the global reanalyses and may be better resolved with higher-resolution assimilation. For example, ERAI has surface wind speeds over the Scoresby Sund region of east Greenland that are too low (Moore et al., 2013); in addition a climatology of katabatic flow along the southeast coast of Greenland demonstrates that ERAI wind speeds are not consistent with observations of topographically forced drainage flow in this region (Oltmanns et al., 2014). Tip jets and polar cyclones are additional examples of Arctic mesoscale phenomena not well represented by the global reanalyses, but the depiction of which may be improved by assimilation of Arctic observations within a regional system (Renfrew et al., 2008; Moore, 2012; Moore and Renfrew, 2014).

The newly developed Arctic System Reanalysis (ASR) (Bromwich et al., 2010), available at the NCAR Research Data Archive (https://climatedataguide.ucar.edu/climate-data/arcticsystem-reanalysis-asr), is an Arctic regional reanalysis that implements the strategies suggested by Bengtsson et al. (2007) and improves the depiction of mesoscale processes in this region. The ASR has garnered cooperative partnerships involving the Arctic terrestrial, sea-ice, ocean and atmospheric communities as it shares its vision with THORPEX-IPY, the World Climate Research Program, and the World Weather Research Programme's Polar Prediction Project in the desire to improve the prediction and understanding of Arctic weather and climate and establish a strong link with global numerical weather prediction centres. The ASR blends modelling and observations to provide a high-resolution description in space and time of the atmosphere-sea ice-land surface system of the greater Arctic during the period 2000-2012. Although similar in concept to the global reanalyses, ASR's focus on Arctic observations and their assimilation (atmosphere and land surface) has resulted in an improved analysis of regional meteorological phenomena and boundary layer processes for this region.

The strategy of this study is to assess the performance of the ASR $30 \mathrm{~km}$ version 1 (ASRv1) by comparing results with observations for 1 year. To contextualize the ASRv1 results, the ERAI is also compared with observations in parallel, in order to assess where the ASRv1 performs well and to highlight issues that may need further improvement in both the analysis and forecast fields. December 2006-November 2007 was chosen for comparison, as the forecast model used in ASRv1 underwent rigorous sensitivity testing during this time (Wilson et al., 2011,2012). This endeavour produced high-quality controlled surface, upper-level, precipitation and radiation observations that are readily available for comparison. Part of this period also overlaps with the fourth International Polar Year (March 2007-March 2009), a scientific programme of intense focus on the Arctic and Antarctic. Although the variability of the full period of the ASR (2000-2012) depends on the interannual variability of not only the atmospheric state itself but also the availability of observations for any particular year, a study of this aspect is beyond the scope of this assessment.

The manuscript is structured as follows. Section 2 describes the characteristics of the ASRv1 and ERAI, including horizontal and vertical resolutions, assimilation approaches and land-surface characteristics. Section 3 compares monthly and annual results for each reanalysis with observations from the surface and free troposphere. State variables including near-surface (upper-level) temperature, dew-point (relative humidity), surface pressure (geopotential height) and horizontal wind speed have been chosen in order to assess the analysis of the ASRv1, as these variables represent the mean state of the atmosphere. Analysis of these variables provides a comprehensive evaluation of the effectiveness in assimilating heterogeneous and sparse observation data across the entire domain and reflects areas where both horizontal and vertical resolutions are important. Section 4 compares ASRv1 and ERAI forecast precipitation and key aspects of the surface-energy budget, specifically incident short-wave and downwelling long-wave radiation. The hydrological and radiative qualities of the forecasts fields represent important quantities for climate comparisons (e.g. water and surface-energy budgets). Finally, a summary of the strengths and weaknesses of the ASRv1 as well as the future development strategy are provided in section 5 .

\section{The ASRv1 and ERAI descriptions}

\subsection{Forecast model}

The regional forecast model used in ASRv1 is the fully compressible, Eulerian non-hydrostatic Weather Research and Forecasting model version 3.3.1 (Skamarock et al., 2008) that has been adapted for use over polar environments (Polar WRF) (Hines and Bromwich, 2008; Bromwich et al., 2009; Hines et al., 2011) and evaluated on the ASRv1 domain (Wilson et al., 2011, 2012). Figure 1 shows the domain, which consists of a one-way nest, whereby the outer domain relays information down-scale to the fine-scale inner domain. The outer domain encompasses most of the Northern Hemisphere in order to capture all of the major weather patterns and provide smooth meteorological fields at the lateral boundaries of the inner domain. The inner domain boundaries have been chosen in order to avoid the highest elevations and also retain the headwaters of the major river basins (e.g. Mackenzie, Ob, Lena and Yenisei) that drain fresh water into the Arctic Ocean and are vital to sea-ice formation and the climate of the Arctic. Polar WRF (Figure 1; ASR low-resolution system) uses the staggered Arakawa grid-C with 361 latitude-longitude grid points in each direction at $30 \mathrm{~km}$ horizontal resolution for the inner domain, covering an area of roughly $1.2 \times 10^{8} \mathrm{~km}^{2}$. This is in contrast with the ECMWF Integrated Forecasting System (IFS) model used in the ERAI, which combines atmosphere, land surface and ocean surface components in a hydrostatic, spectral representation of a global domain with a T255 horizontal resolution ( $\sim 79 \mathrm{~km}$ on a reduced Gaussian grid) integrated with a semi-Lagrangian, semi-implicit scheme (Table 1).

The vertical resolutions in the ASRv1 (Polar WRF) and ERAI (IFS) also differ. The Polar WRF uses a terrain-following, dry hydrostatic-pressure vertical coordinate system with 71 levels in the vertical and a constant pressure surface at the top of the model of $10 \mathrm{hPa}$. The lowest full model level is $8 \mathrm{~m}$ above ground level (AGL), with more than 25 levels below $850 \mathrm{hPa}$. The ERAI uses a 60-level hybrid sigma-pressure vertical coordinate system with a higher model top of $0.1 \mathrm{hPa}$. The ERAI's lowest full-model level is centred at $10 \mathrm{~m}$ AGL with 12 levels below $850 \mathrm{hPa}$. Mid-tropospheric vertical layer spacing is similar for the ASRv1 and ERAI $(\sim 0.5 \mathrm{~km})$ with $0.8 \mathrm{~km}($ ASRv1)/1 km (ERAI) resolution near the tropopause and above. With the higher model top, more of the stratosphere and lower mesosphere are represented by the ERAI, with a vertical spacing of $1.5 \mathrm{~km}$ in this part of the atmosphere (Uppala et al., 2005; Dee et al., 2011).

The ERAI surface and upper air model-level data are used to provide the initial and lateral boundary conditions on the outer grid for Polar WRF. Spectral nudging is utilized on temperature, geopotential height and wind components above $100 \mathrm{hPa}$ (top 20 vertical levels) on the inner domain (all levels in the outer domain) in order to nudge the model forecast toward the ERAI state (Waldon et al., 1996; von Storch et al., 2000). Wavenumber 11 is selected as the top wavenumber to nudge in both the $x$ and $y$ directions of the Polar WRF grid, meaning only the larger-scale synoptic conditions (wavelengths $>1000 \mathrm{~km}$ ) are nudged. The nudging coefficients for all three variables are $0.0003 \mathrm{~s}^{-1}$, which represents approximately $56 \mathrm{~min}$ in relaxation time. The Polar WRF has upper-level damping over the top $8 \mathrm{~km}$ of the atmosphere and gravity wave drag options that limit gravity wave interference at the top of the model. 


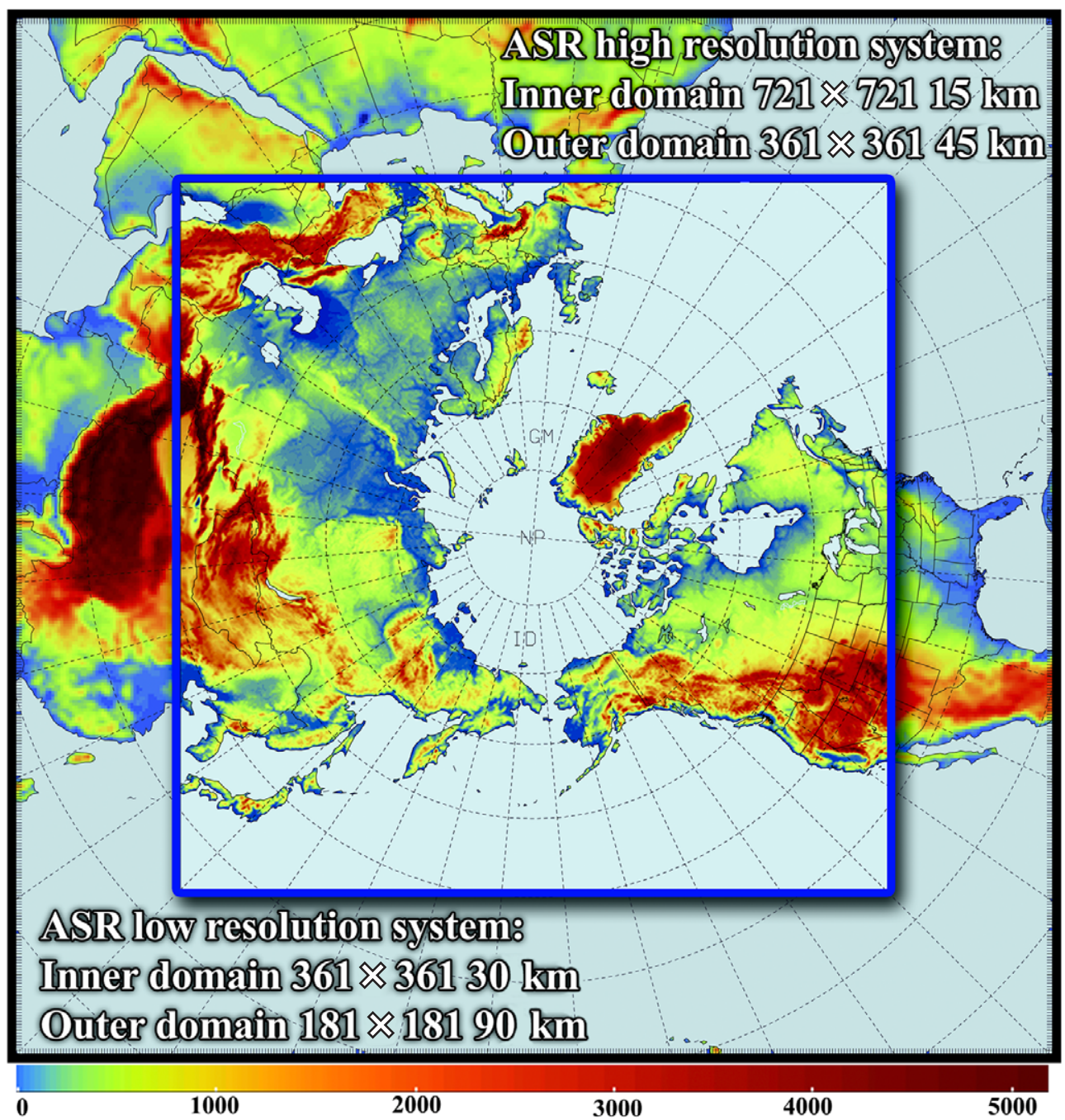

Figure 1. The ASRv1 inner and outer domains along with terrain height (shaded). The low-resolution domain ( $30 \mathrm{~km})$ is analysed in this study. The number of grid points in each direction and horizontal resolution are provided in the lower-left corner. High-resolution ASRv2 (15 km) is currently being conducted, and domain information pertaining to this version is provided in the upper-right corner.

The Polar WRF physics configuration consists of the Goddard microphysics scheme (Tao and Simpson, 1993; Tao et al., 2003), the Kain-Fritsch cumulus parametrization (Kain and Fritsch, 1990, 1993; Kain, 2004), the RRTMG long-wave and short-wave radiation schemes (Mlawer et al., 1997; Iacono et al., 2008), the Noah Land Surface Model (LSM) (Chen and Dudhia, 2001), and the Mellor-Yamada-Nakanishi-Niino (MYNN) (Nakanishi, 2001; Nakanishi and Niino, 2004, 2006) 2.5-level planetary boundary layer (PBL) and complimentary surface-layer schemes. Modifications to the Polar WRF (Hines and Bromwich, 2008; Bromwich et al., 2009; Hines et al., 2011) have focused on improvements to the Noah LSM, including the use of fractional sea ice within each grid cell and the specification of a number of sea-ice characteristics, including thickness, snow cover on sea ice and albedo. Changes to heat transfer and a revised surface-energy balance calculation have also improved the performance of the Polar WRF over all snow and ice surfaces.

\subsection{Data assimilation}

The ERAI uses a 12-hourly analysis cycle centred on analyses produced every $6 \mathrm{~h}$ (0000, 0600 UTC, etc.), combining observations with forecast model data during this time in order to describe the evolution of the atmosphere and land surface (Dee et al., 2011). The analysis is then used as initial conditions to run the forecast model, producing the next model forecast that is combined with observations to produce the next analysis. This process involves $4 \mathrm{D}$ variational assimilation (4D-Var), meaning that observations are assimilated at the time they are observed and multiple iterations of the forecast model ensure that the assimilated data reflect the evolution of the atmospheric state. The ASRv1 uses a simpler but much less computationally-demanding assimilation scheme (WRFDA), producing an analysis every $3 \mathrm{~h}$ by implementing a 3D-Var technique (Barker et al., 2004). Instead of multiple model iterations, a $3 \mathrm{~h}$ forecast is made and then observations within $\pm 1.5 \mathrm{~h}$ of the analysis time are assimilated to produce a new set of initial conditions for the next forecast in time. With both systems, the model first-guess fields are important as they carry forward in time assimilated observations and advect historical atmospheric information from data-rich to data-sparse regions within the domain.

Atmospheric observations assimilated by the ASRv1 and ERAI are similar and include conventional observations (synoptic, METAR, ship, buoy and radiosonde), satellite observations (QuickSCAT, SSM/I - sea-surface wind speed), satellite radiance data (AMSUA, AMSUB, AIRS, MHS, HIRS3, HIRS4) and GPS (RO, IPW). See Dee et al. (2011) for a complete listing of assimilated data in the ERAI. For the land surface, the ASRv1 implements the High Resolution Land Data Assimilation System (HRLDAS) (Chen et al., 2007), which assimilates snow cover and depth, observed vegetation fraction, and albedo from the National Aeronautics and Space Administration (NASA) and National Oceanic and Atmospheric Administration's (NOAA) National Environmental Satellite, Data, and Information Service (NESDIS) satellite observations. Many of these parameters are updated weekly using Moderate Resolution Imaging Spectroradiometer (MODIS) data. The ERAI uses the Tiled ECMWF Scheme for Surface Exchanges over Land (TESSEL), 


\section{H. Bromwich et al.}

Table 1. ASRv1- and ERAI-model, land-surface and data-assimilation characteristics.

\begin{tabular}{|c|c|c|}
\hline Characteristics & ASRv1 & ERAI \\
\hline Domain & Greater Arctic (north of $\sim 40^{\circ} \mathrm{N}$ ) & Global \\
\hline Full period & $2000-2012$ & 1979 to present \\
\hline Model & $\begin{array}{l}\text { Polar WRF } 3.3 .1 \text { coupled to the NOAH LSM, forced } \\
\text { with ERAI lateral boundary conditions, spectrally } \\
\text { nudged above } 100 \mathrm{hPa}\end{array}$ & $\begin{array}{l}\text { ECMWF IFS (coupled atmosphere, land surface, } \\
\text { and ocean wave components) }\end{array}$ \\
\hline Dynamical core & Fully compressible, Euler non-hydrostatic & Hydrostatic, spectral \\
\hline Vertical coordinate & Terrain-following, dry hydrostatic-pressure & Hybrid-sigma pressure \\
\hline Horizontal resolution and grid & $30 \mathrm{~km} /$ Arakawa C-grid staggering & $\begin{array}{l}\text { T255/N128 reduced Gaussian grid }(\sim 79 \mathrm{~km} \\
\text { globally })\end{array}$ \\
\hline Vertical resolution and model top & 71 vertical levels with $10 \mathrm{hPa}$ top & 60 vertical levels with $0.1 \mathrm{hPa}$ top \\
\hline Land surface & HRLDAS with NOAH LSM & TESSEL \\
\hline SST & ERAI & $\begin{array}{l}\text { NCEP 2DVAR (January 1979-June 2001); NCEP } \\
\text { OISST V2 (July-December 2001); NCEP RTG } \\
\text { (January 2002-January 2009); OSTIA (February } \\
2009 \text { to present). }\end{array}$ \\
\hline \multirow[t]{4}{*}{ Sea-ice } & $\begin{array}{l}\text { SSMI } 25 \mathrm{~km} \text { (January 2000-June 2002; October } \\
\text { 2011-December 2012); AMSRE } 6.25 \mathrm{~km} \text { (June } \\
\text { 2002-October 2011) }\end{array}$ & Same as SST \\
\hline & $\begin{array}{l}\text { Varying; based on same data as concentration except } \\
\text { PIOMASS (Schweiger et al., 2011) was used for } \\
\text { (October 2011-December 2012) }\end{array}$ & Fixed \\
\hline & $\begin{array}{l}\text { Annually varying seasonal cycle based on } \\
\text { melt/freeze date observations }\end{array}$ & Fixed monthly climatology \\
\hline & Seasonally varying & $\mathrm{N} / \mathrm{A}$ \\
\hline Snow cover and depth & NCEP final analysis & NOAA/NESDIS daily IMS \\
\hline Land-surface albedo & $\begin{array}{l}\text { MODIS updated every } 8 \text { days/Greenland - updated } \\
\text { daily }\end{array}$ & $\begin{array}{l}\text { Monthly mean climatology based on 16-day } \\
\text { MODIS from } 2000 \text { to } 2003\end{array}$ \\
\hline Orography & $\begin{array}{l}\text { USGS GTOPO 2'/Greenland - } 1 \text { km DEM (Bamber } \\
\text { et al., 2001) }\end{array}$ & $\begin{array}{l}\text { USGS GTOPO 30"/Greenland - 30" KMS DEM } \\
\text { (Ekholm, 1996) }\end{array}$ \\
\hline Vegetation & MODIS - updated every 8 days & GLCC derived from 1 year of AVHRR \\
\hline Soil & Initialized with ERAI soil temperature and moisture & $\begin{array}{l}\text { Soil analysis for IFS based on } 2 \mathrm{~m} \text { temperature and } \\
\text { relative humidity observations }\end{array}$ \\
\hline Method & $\begin{array}{l}\text { 3-hourly analysis cycle assimilating observations } \\
\text { within } \pm 1.5 \mathrm{~h} \text { of analysis }\end{array}$ & $\begin{array}{l}\text { 12-hourly analysis window centered on analyses } \\
\text { every } 6 \mathrm{~h} \text { assimilating observations at the time they } \\
\text { are observed }\end{array}$ \\
\hline Background error & Based on 12 and $24 \mathrm{~h}$ Polar WRF forecasts & $\begin{array}{l}\text { Static ensemble based correlations and state } \\
\text { dependent variances (see Fisher and Courtier, 1995; } \\
\text { Fisher, 2003) }\end{array}$ \\
\hline Data & $\begin{array}{l}\text { Conventional data and limited array of satellite data } \\
\text { (see text for details) }\end{array}$ & $\begin{array}{l}\text { Conventional data and extensive array of satellite } \\
\text { data (see Dee et al., 2011) }\end{array}$ \\
\hline
\end{tabular}

with four-layer soil and snow updates to the temperature and moisture, high and low vegetation types based on the Global Land Cover Characteristics (GLCC) data set at $1 \mathrm{~km}$ resolution derived from the Advanced Very High Resolution Radiometer (AVHRR), and a snow scheme with different treatments for open-area snow and snow shielded by high vegetation (Dee et al., 2011).

\section{Surface and upper-air analyses}

For the ASRv1 analysis, near-surface air and dew-point temperatures are calculated using potential temperatures and mixing ratios from the bottom model level, respectively. The ERAI uses a separate temperature and humidity optimization for their publically available surface analysis (Simmons et al., 2010), and these data are used directly for temperature and dew-point. Temperature, dew-point and surface pressure have been corrected for differences between reanalyses and observation heights. Wind speeds at two vertical levels (above and below $10 \mathrm{~m}$ AGL) in the ASRv1 are calculated using the zonal and meridional components of the wind, and then linearly interpolated between the two levels in order to obtain $10 \mathrm{~m}$ wind speed. For the ERAI, $10 \mathrm{~m}$ wind is used directly. All upper-level data have been interpolated from model-level data to isobaric surfaces for both the ASRv1 and ERAI. Even with tight quality control measures, comparing single-site observations with gridded cell data from the reanalyses makes interpreting the results a challenge.
Although results are similar using the nearest point to the latitude and longitude of each station location (not shown), we utilize a bilinear interpolation among the four closest grid-points for all comparisons in this study. It should be noted here that except for stations that are rejected by the data assimilation systems, observations used for this comparison are assimilated in the ASRv1 and ERAI. Therefore, the reanalyses are not explicitly independent from the observations. Confidence intervals for the mean statistics from the ASRv1 and ERAI are calculated using the $t$-value for $95 \%\left(t_{95}\right)$ and the standard error of the means (SE).

\subsection{Near-surface variables}

Near-surface variables from the ASRv1 and ERAI have been compared with $\sim 4500$ surface stations from the National Climatic Data Center (NCDC; http://www.ncdc.noaa.gov/) in order to compare the large-scale performance of the ASRv1. These variables are evaluated at $3 \mathrm{~h}$ intervals, and the ERAI is interpolated linearly in time to produce values in between analysis times (0300, 0900, 1200 and 1500). Table 2 shows the monthly and annual biases, root mean squared errors (RMSEs) and correlations for all variables for the ASRv1 and ERAI, along with the percentage of stations with significant biases $\left(\% \neq H_{0}\right)$ based on a Student's $t$-test and $p<0.05$ for the period of December 2006-November 2007. A comparison of the variance between the two reanalyses reveals that their standard errors are small and most of the 
The Arctic System Reanalysis

Table 2. Near-surface monthly and annual mean statistics for the ASRv1 and ERAI compared to NCDC observations.

\begin{tabular}{|c|c|c|c|c|c|c|c|c|c|c|c|c|c|c|c|c|}
\hline \multirow[b]{3}{*}{ Month } & \multicolumn{8}{|c|}{$2 \mathrm{~m}$ temperature $\left({ }^{\circ} \mathrm{C}\right)$} & \multicolumn{8}{|c|}{$2 \mathrm{~m} \operatorname{dew}-\operatorname{point}\left({ }^{\circ} \mathrm{C}\right)$} \\
\hline & \multicolumn{4}{|c|}{ Bias } & \multicolumn{2}{|c|}{ RMSE } & \multicolumn{2}{|c|}{ Correlation } & \multicolumn{4}{|c|}{ Bias } & \multicolumn{2}{|c|}{ RMSE } & \multicolumn{2}{|c|}{ Correlation } \\
\hline & ASRv1 & $\% \neq H_{0}$ & ERAI & $\% \neq H_{0}$ & ASRv1 & ERAI & ASRv1 & ERAI & ASRv1 & $\% \neq H_{0}$ & ERAI & $\% \neq H_{0}$ & ASRv1 & ERAI & ASRv1 & ERAI \\
\hline 1 & 0.17 & 23 & 0.35 & 37 & 1.44 & 2.17 & 0.96 & 0.92 & 0.29 & 34 & 0.62 & 47 & 1.92 & 2.23 & 0.94 & 0.92 \\
\hline 2 & 0.05 & 16 & 0.28 & 34 & 1.33 & 2.11 & 0.96 & 0.92 & 0.07 & 31 & 0.67 & 51 & 1.90 & 2.28 & 0.94 & 0.91 \\
\hline 3 & 0.02 & 13 & 0.25 & 32 & 1.37 & 2.09 & 0.96 & 0.92 & 0.02 & 29 & 0.55 & 49 & 1.79 & 2.22 & 0.93 & 0.90 \\
\hline 4 & 0.05 & 12 & 0.23 & 29 & 1.27 & 1.97 & 0.97 & 0.93 & -0.01 & 34 & 0.45 & 47 & 1.73 & 2.14 & 0.92 & 0.88 \\
\hline 6 & 0.03 & 20 & 0.25 & 37 & 1.35 & 1.99 & 0.95 & 0.91 & -0.34 & 45 & 0.02 & 62 & 1.70 & 1.98 & 0.90 & 0.85 \\
\hline 7 & 0.01 & 21 & 0.27 & 40 & 1.29 & 1.93 & 0.95 & 0.91 & -0.04 & 47 & -0.09 & 68 & 1.58 & 1.90 & 0.89 & 0.84 \\
\hline 8 & 0.05 & 18 & 0.28 & 35 & 1.25 & 1.87 & 0.95 & 0.91 & -0.15 & 41 & -0.03 & 58 & 1.53 & 1.81 & 0.90 & 0.85 \\
\hline 9 & 0.09 & 15 & 0.25 & 34 & 1.23 & 1.83 & 0.96 & 0.92 & -0.27 & 38 & 0.11 & 48 & 1.59 & 1.85 & 0.93 & 0.90 \\
\hline 10 & 0.14 & 16 & 0.27 & 33 & 1.25 & 1.85 & 0.96 & 0.92 & -0.01 & 30 & 0.24 & 41 & 1.54 & 1.82 & 0.94 & 0.92 \\
\hline 11 & 0.26 & 25 & 0.36 & 38 & 1.43 & 1.95 & 0.95 & 0.92 & 0.12 & 33 & 0.50 & 47 & 1.80 & 2.05 & 0.94 & 0.92 \\
\hline \multirow[t]{2}{*}{ Annual } & 0.10 & 19 & 0.29 & 35 & 1.33 & 1.99 & 0.96 & 0.92 & -0.02 & 36 & 0.32 & 52 & 1.72 & 2.04 & 0.92 & 0.88 \\
\hline & \multicolumn{8}{|c|}{ Surface pressure $(\mathrm{hPa})$} & \multicolumn{8}{|c|}{$10 \mathrm{~m}$ wind speed $\left(\mathrm{m} \mathrm{s}^{-1}\right)$} \\
\hline Month & ASRv1 & $\% \neq H_{0}$ & ERAI & $\% \neq H_{0}$ & ASRv1 & ERAI & ASRv1 & ERAI & ASRv1 & $\% \neq H_{0}$ & ERAI & $\% \neq H_{0}$ & ASRv1 & ERAI & ASRv1 & ERAI \\
\hline 12 & 0.07 & 8 & 0.10 & 14 & 0.90 & 1.07 & 0.99 & 0.99 & -0.14 & 69 & 0.63 & 79 & 1.91 & 2.34 & 0.71 & 0.66 \\
\hline 1 & 0.11 & 9 & 0.12 & 16 & 0.91 & 1.11 & 0.99 & 0.99 & -0.11 & 71 & 0.68 & 79 & 1.94 & 2.37 & 0.73 & 0.68 \\
\hline 2 & 0.07 & 8 & 0.10 & 15 & 0.87 & 1.03 & 0.99 & 0.99 & -0.18 & 66 & 0.51 & 76 & 1.87 & 2.24 & 0.72 & 0.67 \\
\hline 3 & 0.04 & 7 & 0.01 & 12 & 0.93 & 1.08 & 0.99 & 0.99 & -0.25 & 66 & 0.41 & 73 & 1.87 & 2.22 & 0.73 & 0.67 \\
\hline 4 & 0.01 & 11 & -0.04 & 18 & 0.79 & 0.91 & 0.99 & 0.98 & -0.35 & 67 & 0.18 & 72 & 1.76 & 2.04 & 0.72 & 0.65 \\
\hline 5 & 0.00 & 13 & 0.14 & 19 & 0.81 & 0.94 & 0.99 & 0.98 & -0.40 & 71 & 0.20 & 72 & 1.77 & 2.07 & 0.70 & 0.62 \\
\hline 6 & -0.01 & 15 & -0.21 & 23 & 0.79 & 0.91 & 0.99 & 0.98 & -0.34 & 69 & 0.18 & 72 & 1.67 & 1.94 & 0.67 & 0.61 \\
\hline 7 & 0.01 & 19 & -0.24 & 27 & 0.78 & 0.91 & 0.99 & 0.98 & -0.29 & 71 & 0.27 & 76 & 1.64 & 1.94 & 0.66 & 0.60 \\
\hline 8 & 0.00 & 16 & -0.21 & 24 & 0.77 & 0.90 & 0.99 & 0.98 & -0.27 & 68 & 0.29 & 75 & 1.63 & 1.93 & 0.66 & 0.60 \\
\hline 9 & 0.02 & 12 & -0.12 & 18 & 0.78 & 0.92 & 0.99 & 0.99 & -0.20 & 67 & 0.48 & 77 & 1.69 & 2.07 & 0.70 & 0.64 \\
\hline 10 & 0.01 & 12 & -0.07 & 20 & 0.81 & 0.95 & 0.99 & 0.98 & -0.16 & 67 & 0.48 & 78 & 1.70 & 2.09 & 0.71 & 0.65 \\
\hline 11 & 0.06 & 9 & 0.04 & 15 & 0.85 & 0.99 & 0.99 & 0.99 & -0.18 & 70 & 0.59 & 78 & 1.86 & 2.28 & 0.72 & 0.66 \\
\hline Annual & 0.03 & 12 & -0.03 & 18 & 0.83 & 0.98 & 0.99 & 0.99 & -0.24 & 69 & 0.41 & 76 & 1.78 & 2.13 & 0.70 & 0.64 \\
\hline
\end{tabular}

$\% \neq H_{0}$ : denotes the percentage of stations where the monthly means are significantly different from observations. The annual value is the average of the monthly values.

Italicized values indicate where ASRv1 and ERAI are not statistically different based on a Student's two-tailed $t$-test.

differences between them are statistically significant (insignificant differences are found only in surface pressure).

Figure 2(a,b) shows annual $2 \mathrm{~m}$ temperature biases for all the stations for the ASRv1 and ERAI, respectively. Across much of the higher latitudes throughout Europe, Siberia and North America, the ASRv1 biases are small and cool. Larger biases are found in central Asia and in the western United States, where topography is much more complex. The ERAI presents warm biases across much of the domain, particularly across Siberia Alaska and western North America. Low RMSE values in the ASRv1 and ERAI almost domain-wide (not shown) demonstrate accurate assimilations of observations and they have high correlations compared with observations. Seasonally, the ASRv1 and ERAI have small warm biases during all months, although much less than $1{ }^{\circ} \mathrm{C}$ (Table 2). The ASRv1 demonstrates nearly zero $2 \mathrm{~m}$ temperature biases during the spring and summer, with smaller biases and RMSEs and larger correlations than the ERAI. Compared with observations, fewer stations in the ASR exhibit significant biases (19\%) than the ERAI (35\%).

Similar results are found for $2 \mathrm{~m}$ dew-point temperatures, although there is a negative bias in the ASRv1 from late spring through early autumn, which is strongly reflected in the annual mean biases of the individual stations (Figure 2(c)). Overall, positive annual mean $2 \mathrm{~m}$ temperature and negative $2 \mathrm{~m}$ dew-point biases suggest dry conditions (larger dew-point depressions) in ASRv1 that may explain the predominately dry biases in the hydrological cycle (section 4.1). The ERAI $2 \mathrm{~m}$ dewpoint biases (most of the individual stations in Figure 2(d)) show small positive biases, which considering small warm air temperature biases, indicates that the relative humidity is well captured.

The ASRv1 and ERAI perform very well with surface pressure, as annual mean biases are only a few hundredths of a hPa for both reanalyses, with small RMSEs and high correlations. This means that the synoptic setting in the ASRv1 as in the ERAI is very well captured in the analysis fields, with negligible differences in the locations of storm systems throughout the domain. Figure 2(e,f) shows very small biases over most of the domain for the ASRv1 and ERAI, apart from areas of complex terrain where the surface pressure biases are slightly larger and negative (western United States).

Near-surface wind, especially over complex terrain, is often difficult to capture due to highly variable fine-scale (local) wind effects that are sensitive to station location as well as model terrain, which are not always well represented on the model grid. However, the ASRv1's annual domain-mean negative wind bias is $-0.24 \mathrm{~m} \mathrm{~s}^{-1}$, with most stations demonstrating annual mean biases of $\pm 1 \mathrm{~m} \mathrm{~s}^{-1}$ (Figure 2(g)). The ERAI $10 \mathrm{~m}$ annual domain-mean bias is also small but positive $\left(0.41 \mathrm{~m} \mathrm{~s}^{-1}\right)$, largely a result of positive biases of $1-3 \mathrm{~m} \mathrm{~s}^{-1}$ across Europe and Asia (Figure 2(h)). The IFS model used in the ERAI has been demonstrated to have overly strong turbulent mixing (Bechtold et al., 2008; Jung et al., 2010), which leads to weak inversions, warmer temperatures near the surface and stronger horizontal wind. Although the ASRv1 correlations are lower for $10 \mathrm{~m}$ wind speed compared with the other three surface variables, they are higher than the ERAI and statistically significant for all months, with approximately $5-10 \%$ fewer stations demonstrating significant biases compared with observations.

\subsection{Upper-air analysis}

Twice-daily (0000 and 1200 UTC) soundings from the Integrated Global Radiosonde Archive (IGRA)-derived version-2 (Durre and Yin, 2008) are used to compare the ASRv1 and ERAI analyses above the surface. Out of a pool of 292 possible stations at each level, only those stations reporting at least $50 \%$ of the monthly radiosonde observations are included in the comparison of temperature, geopotential height, relative humidity and horizontal wind speed. Figure 3 shows mean vertical profiles of annual mean biases, RMSEs and correlations for selected isobaric levels between 1000 and $10 \mathrm{hPa}$. Error bars represent the 95\% confidence intervals of annual means based on a Student's $t$-test. 
(a)

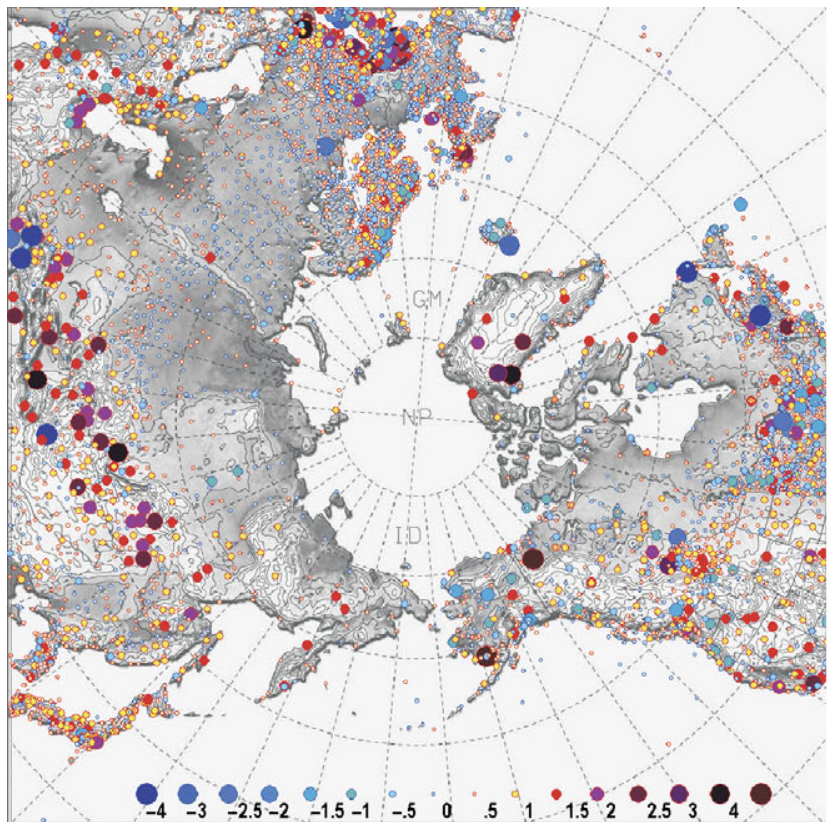

(c)

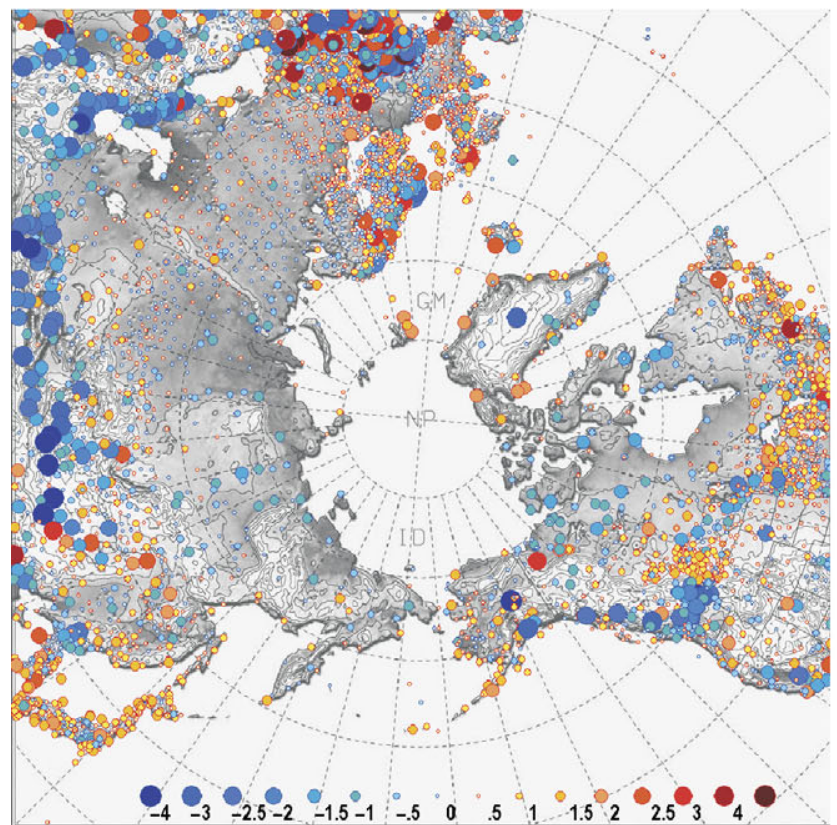

(b) ERAI $2 \mathrm{~m}$ Temperature $\left({ }^{\circ} \mathrm{C}\right)$

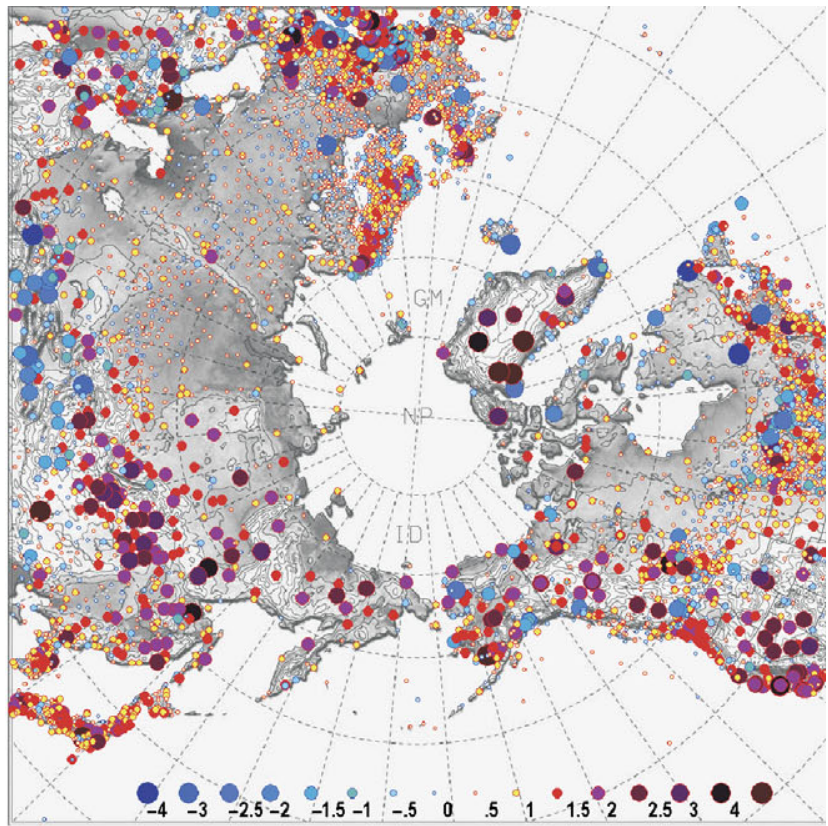

(d)

$2 \mathrm{~m}$ Dew-point $\left({ }^{\circ} \mathrm{C}\right)$

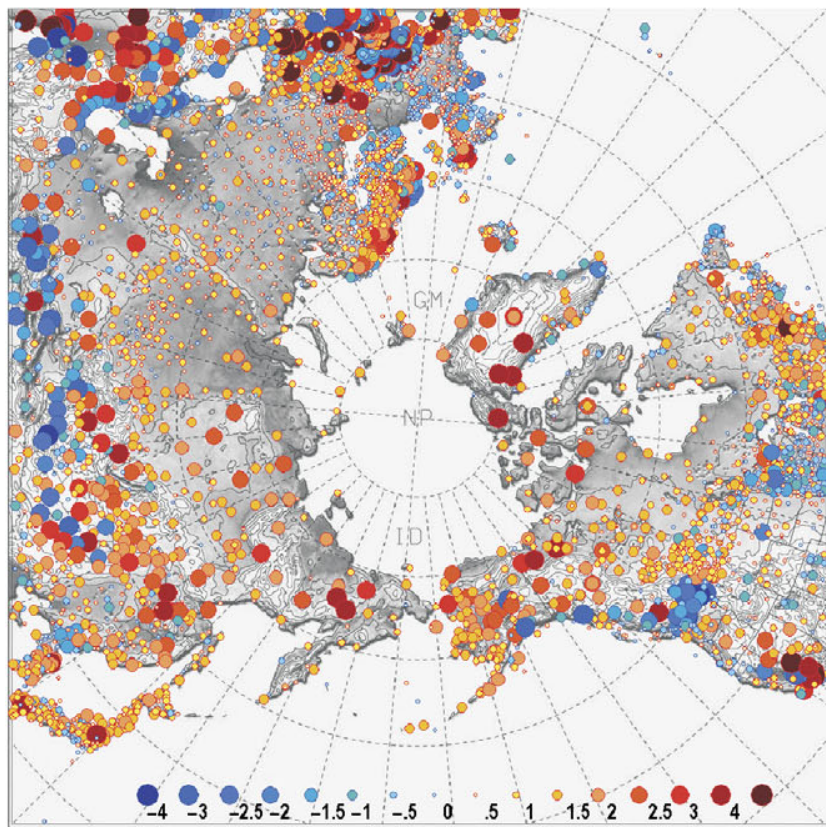

Figure 2. Annual mean biases for the period December 2006-November 2007 for the ASRv1 (a,c,e,g) and ERAI (b,d,f,h) for (a,b) 2 m temperature $\left({ }^{\circ} \mathrm{C}\right),(\mathrm{c}, \mathrm{d}) 2 \mathrm{~m}$ dew-point $\left({ }^{\circ} \mathrm{C}\right),(\mathrm{e}, \mathrm{f})$ surface pressure $(\mathrm{hPa})$ and $(\mathrm{g}, \mathrm{h}) 10 \mathrm{~m}$ wind speed $\left(\mathrm{m} \mathrm{s}^{-1}\right)$. Magnitudes of the biases are given by the colour scale and the size of the symbol.

Figure 4 displays the biases at each station on the $500 \mathrm{hPa}$ level (850 hPa for RH) for ASRv1 and ERAI.

Figure 3(a) shows ASRv1 and ERAI temperatures are similar, with annual mean biases within $\pm 0.2{ }^{\circ} \mathrm{C}$ at nearly all levels for both reanalyses. ASRv1 temperatures are cool compared to IGRA for most levels and ERAI biases are smaller than ASRv1 in the lower atmosphere, though their differences are not statistically significant. ASRv1 annual mean temperature biases are statistically different than ERAI near the tropopause $(200-300 \mathrm{hPa})$, with each reanalysis on either side of zero in this region of the atmosphere. RMSE values in ASRv1 are smaller than ERAI below $100 \mathrm{hPa}$, while ERAI RMSEs are smaller above this level. Seasonally (not shown), the ASRv1 temperature analysis is consistent with the annual results, with biases no greater than $\pm 0.24^{\circ} \mathrm{C}$, small RMSE values $(0.69-1.54)$ and high correlations (0.91-0.98, lowest in the summer). Figure 4(a) shows that warm biases in the ASRv1 at $500 \mathrm{hPa}$ can be found in most of North America and western Europe, with a large expanse of negative temperature biases from eastern Europe through Asia. These temperature biases are similar to the ERAI (Figure 4(b)), with only slightly smaller biases in western North America in the ASRv1.

Annual mean geopotential height biases of \pm 2 gpm or less are found at all levels except $100 \mathrm{hPa}$ for the ASRv1 and ERAI (Figure 3(b)). Negative biases are found in the ASRv1 close to the surface and for all levels at/above $300 \mathrm{hPa}$. Positive biases are demonstrated throughout most of the atmosphere for the ERAI. The two reanalysis are not significantly different from one another at any level, as their standard errors of the mean biases are similar. The RMSEs are slightly smaller in the ASRv1 than ERAI, but again the standard errors associated with the mean RMSEs do not differ significantly and the correlations are extremely high $(>0.99)$ for all levels in both reanalyses. Seasonally there is very little change in the biases, RMSEs or correlations at any of the levels for geopotential height. Spatially, both reanalyses show similar biases at most locations throughout the domain (Figure $4(\mathrm{c}, \mathrm{d})$ ). The largest biases are located in eastern Europe through central Asia, although these biases are generally within $20 \mathrm{gpm}(<1 \%$ of the mean 500 hPa geopotential height). 
(e)

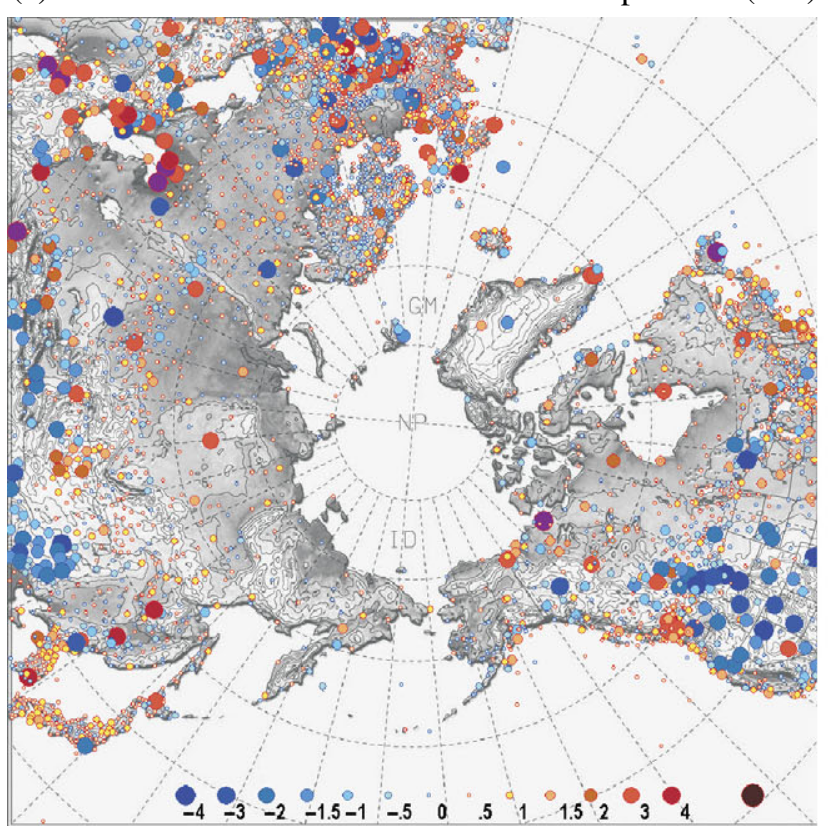

$(\mathrm{g})$

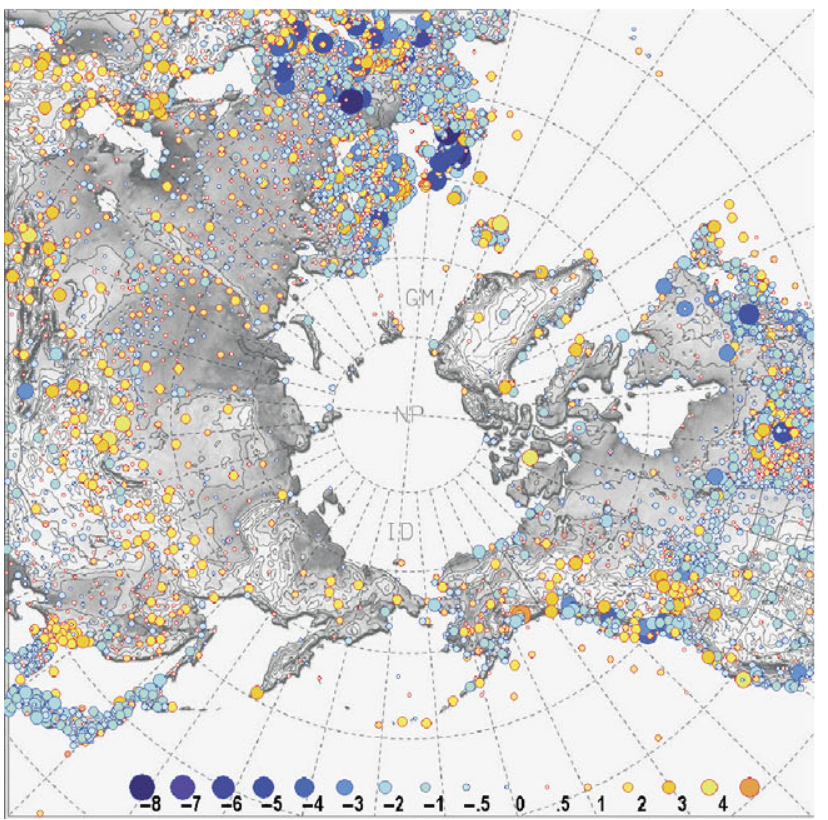

(f)

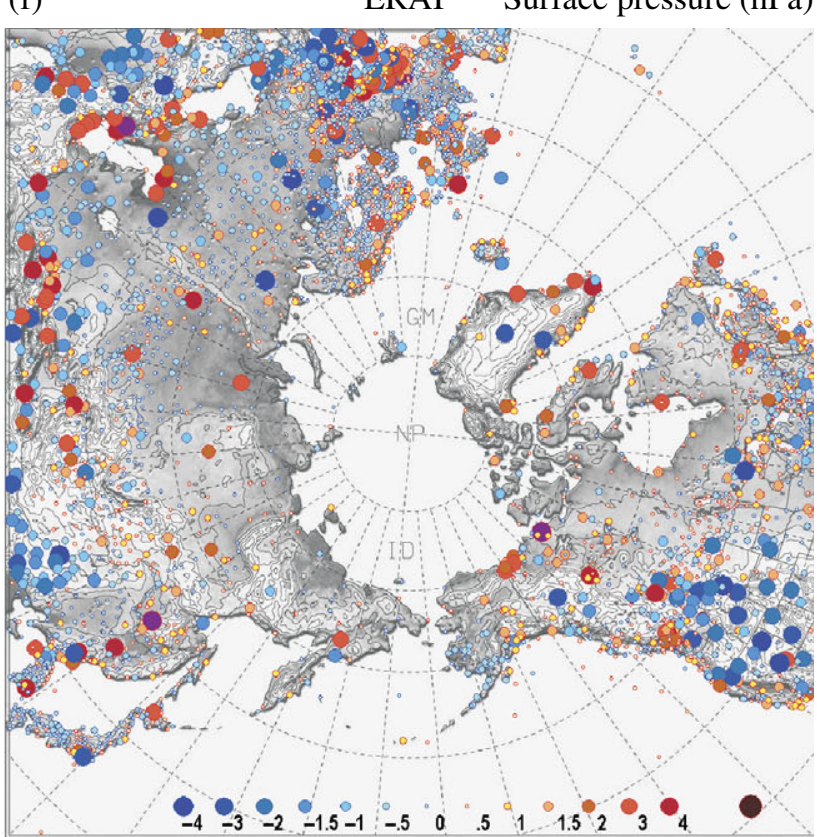

(h)
ERAI Surface pressure ( $\mathrm{hPa})$

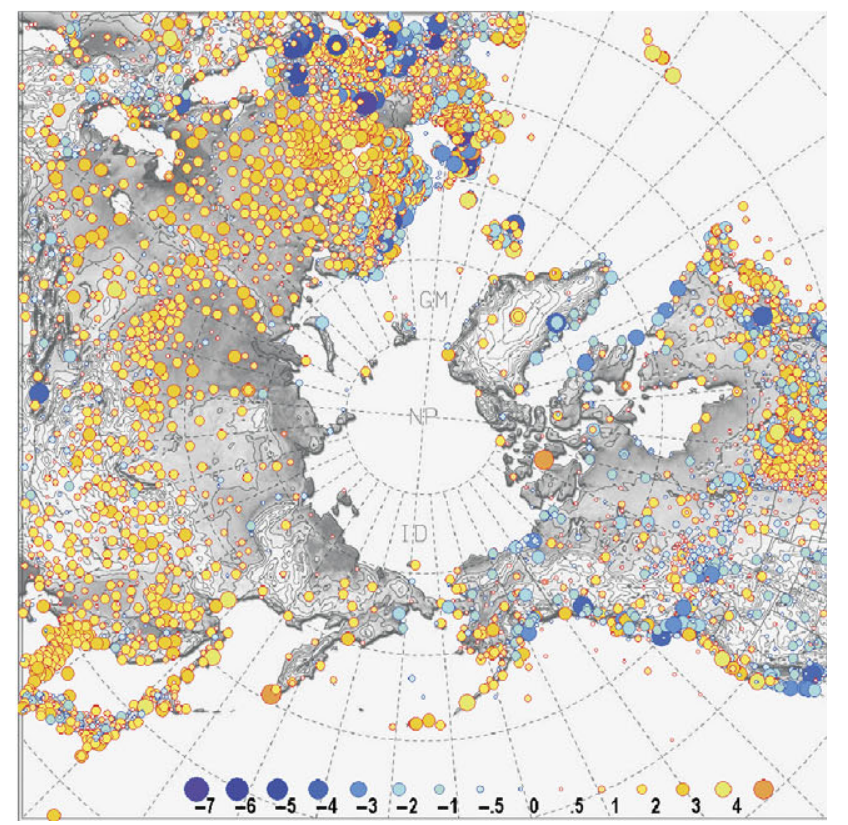

Figure 2. Continued.

Relative humidity biases are similar for the ASRv1 and ERAI, although RMSEs are significantly smaller and correlations are significantly higher in the ASRv1 between 1000 and $500 \mathrm{hPa}$ (Figure $3(\mathrm{c})$ ). Figure $4(\mathrm{e}, \mathrm{f})$ shows positive biases (generally $<5 \%$ of means) throughout most of the midlatitudes, including western Europe, central Asia and along $50^{\circ} \mathrm{N}$ in North America. The Arctic region throughout northern Europe, Siberia, Alaska and northern Canada also reflects negative biases in both reanalyses. The ASRv1 has negative relative humidity biases across Siberia that differ with the ERAI, as well as more stations with positive biases in western Europe. The ERAI's domain-wide mean bias is $\sim 0.1 \%$ larger than the ASRv1, probably a reflection of slightly larger positive biases across the higher terrain of central and eastern Asia.

Figure 3(d) shows that although both reanalyses demonstrate weaker than observed horizontal winds throughout most of the atmosphere, the ERAI wind speed biases are significantly smaller for stations reporting at $1000 \mathrm{hPa}$. The ASRv1 mean annual biases are significantly smaller than ERAI through most of the troposphere and lower stratosphere $(850$ and $200 \mathrm{hPa})$, while the two are nearly identical above $100 \mathrm{hPa}$ (the ASRv1 is nudged to the ERAI in this part of the atmosphere). The ASRv1 demonstrates significantly smaller RMSEs between 925 and $400 \mathrm{hPa}$, with higher correlations in the lower atmosphere as well. Figure $4(\mathrm{~g}, \mathrm{~h})$ shows that horizontal wind-speed biases at $500 \mathrm{hPa}$ are negative across most of the domain, with generally smaller biases in the ASRv1 (consistent with Figure 3(d)).

\section{Forecast precipitation and downwelling radiation}

\subsection{Precipitation}

The ASRv1 and ERAI forecast monthly precipitation totals are compared with gauge observations on land from the Global Historical Climate Network version 2 (GHCN2) (Peterson and Vose, 1997) and the Adjusted Historical Canadian Climate Data (AHCCD) (Mekis and Hogg, 1999). The GHCN2 and AHCCD data have undergone rigorous quality control (Peterson and Easterling, 1994; Easterling and Peterson, 1995; Mekis and Hopkinson, 2004; Mekis, 2005; Devine and Mekis, 2008), including methods to improve wind undercatch, evaporation and adjustments for trace observations, all particularly important 

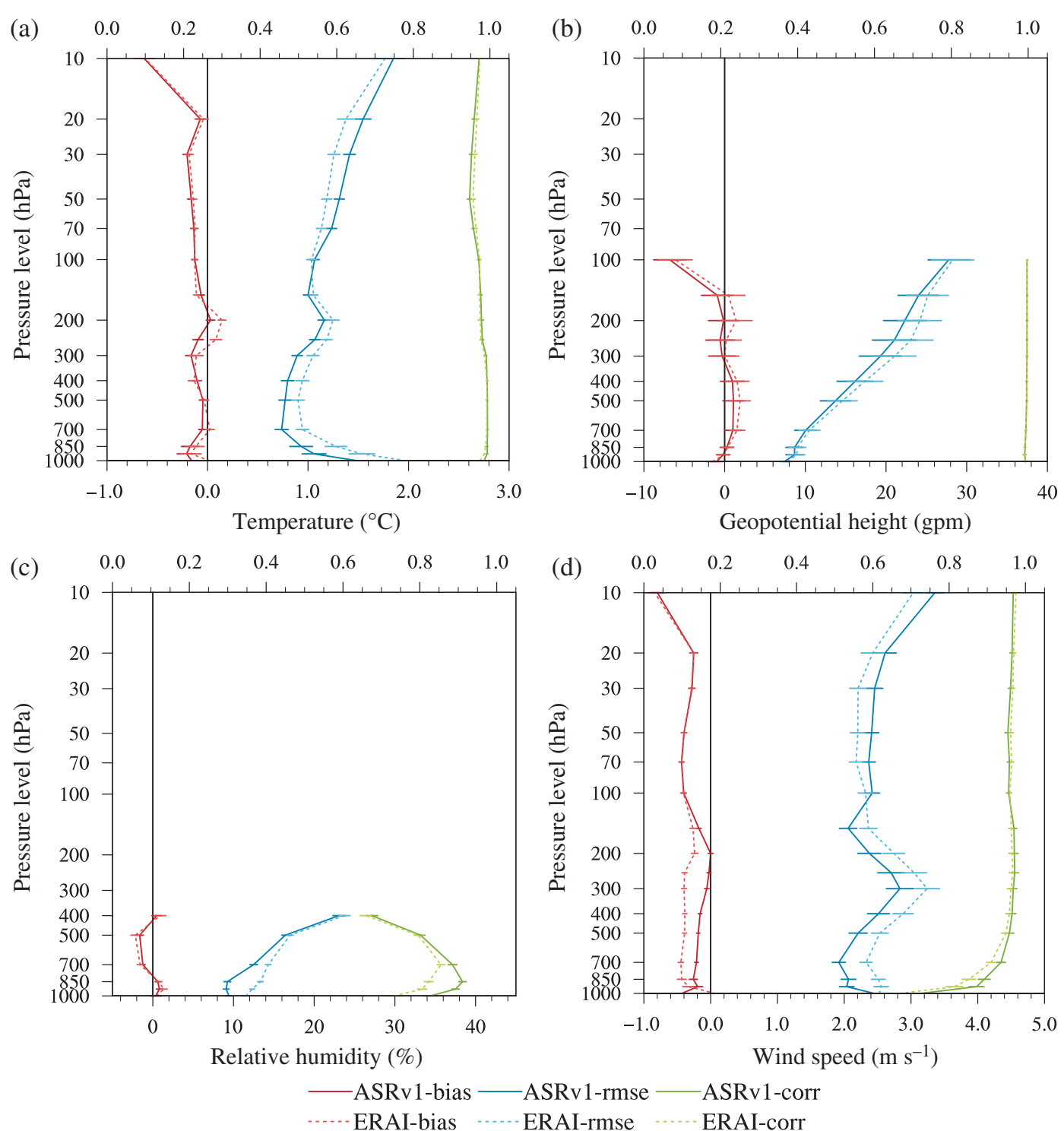

Figure 3. Vertical profiles of annual mean biases (red), RMSEs (blue) and correlations (green) for the ASRv1 (solid lines) and ERAI (dotted lines) for (a) temperature $\left({ }^{\circ} \mathrm{C}\right)$, (b) geopotential height $(\mathrm{gpm})$, (c) relative humidity $(\%)$ and $(\mathrm{d})$ horizontal wind speed $\left(\mathrm{m} \mathrm{s}^{-1}\right)$. Error bars represent the $95 \%$ confidence intervals based on $\pm t_{95} \times \mathrm{SE}$ of all station biases, RMSEs, and correlations at each level. The $y$-axis is log-scaled based on pressure level. Biases and RMSEs are represented by the bottom $\mathrm{x}$-axis and correlation is represented by the top $x$-axis.

for frozen and light precipitation regimes that dominate the Arctic. Only stations with complete annual records are included in this comparison. Further insights are achieved by dividing observations into two regions as their precipitation patterns vary: midlatitude (south of $60^{\circ} \mathrm{N}\left(296\right.$ stations)) and polar $\left(60^{\circ} \mathrm{N}\right.$ and poleward (78 stations)).

Many factors affect precipitation comparisons between station data and model/reanalysis output, including model resolution, observation density and interpolation methods (Accadia et al., 2003; Hofstra et al., 2010; Wolff et al., 2014). To avoid the addition of error by interpolating with reanalyses, we use the ERAI on a $0.75 \times 0.75$ latitude-longitude grid and leave the ASRv1 results on its native projection for the precipitation comparison. All precipitation types for the ASRv1 and ERAI are summed to monthly totals based on 3 and $12 \mathrm{~h}$ forecasts, respectively.

Figure 5 shows monthly and annual total precipitation for the ASRv1, ERAI and observations as well as mean biases of each reanalysis compared with observations. The monthly and annual totals (Figure $5(\mathrm{a})-(\mathrm{c})$ ) shows grand totals of all, midlatitude and polar stations within the domain (or subregion), and their units are $\times 10^{4} \mathrm{~mm}$ for monthly sums and $\times 10^{5} \mathrm{~mm}$ for annual sums. Figure $5(\mathrm{~d})-(\mathrm{f})$ shows the station-mean monthly $(\mathrm{mm})$ and annual biases $(\mathrm{mm})$ compared with observations. For all stations during the cool months (September-March), the ASRv1 forecast precipitation is generally less than observed, with biases ranging from -4.2 to $-10.3 \%$ (Figure $5(\mathrm{a}, \mathrm{d})$ ). Overall, ERAI biases are smaller than the ASRv1 during the same months, ranging from 0.1 to $-6.5 \%$, although the two reanalyses are not significantly different from one another (based on $95 \%$ confidence intervals). From April to August, the ASRv1 generates too much precipitation, with positive biases ranging from 0.6 to $18.2 \%$, while April is the only month overpredicted by the ERAI (9.3\%). Unlike the cool months, the mean biases for June and July are significantly different between the ASRv1 and ERAI. This is the product of too much precipitation over land in the ASRv1 during the summertime in the midlatitudes, where biases for June and July are 25.2 and $14.0 \%$, respectively (Figure 5(b,e)).

This seasonal difference between the warm and cool seasons has already been shown in sensitivity simulations using the Polar WRF over the ASRv1 domain (Wilson et al., 2011, 2012), and a similar analysis was repeated for this study. An investigation of the diurnal cycle of near-surface dew-point temperature in ASRv1 (not shown) shows positive $2 \mathrm{~m}$ dew-point biases during the afternoon hours compared with observations, reflecting increased low-level moisture ( $2 \mathrm{~m}$ temperatures during this time are well represented). The increase in low-level moisture in summer is tied to excessive evaporation and increased convective available potential energy (CAPE). These moisture and CAPE errors result in more convection and large summertime precipitation biases, 
(a)

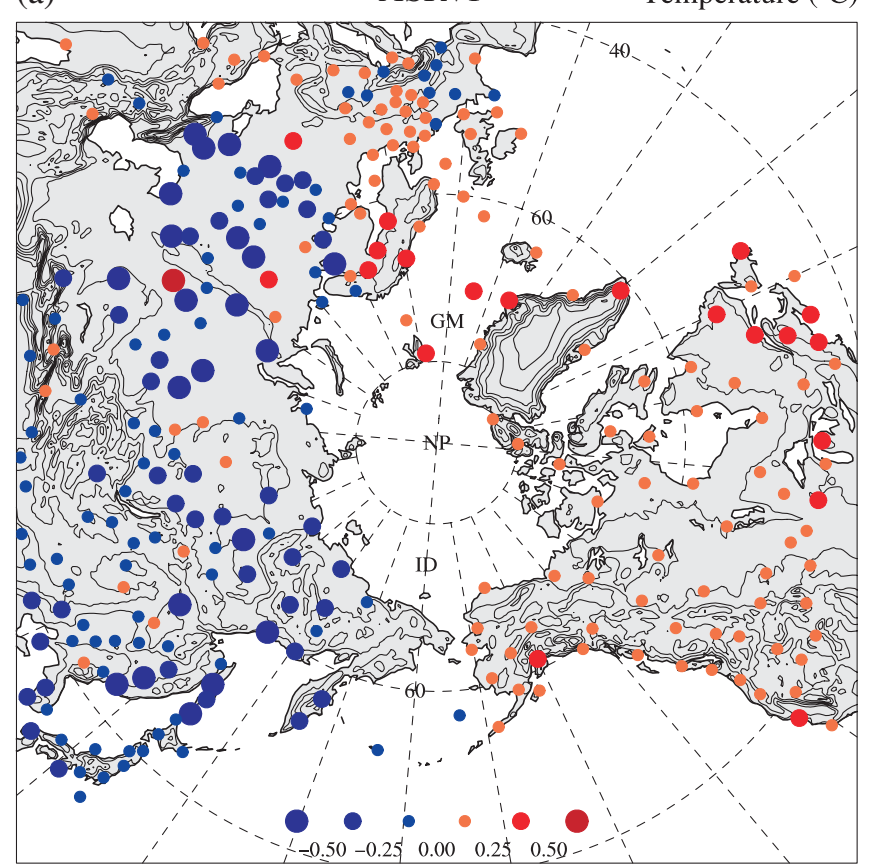

(c)

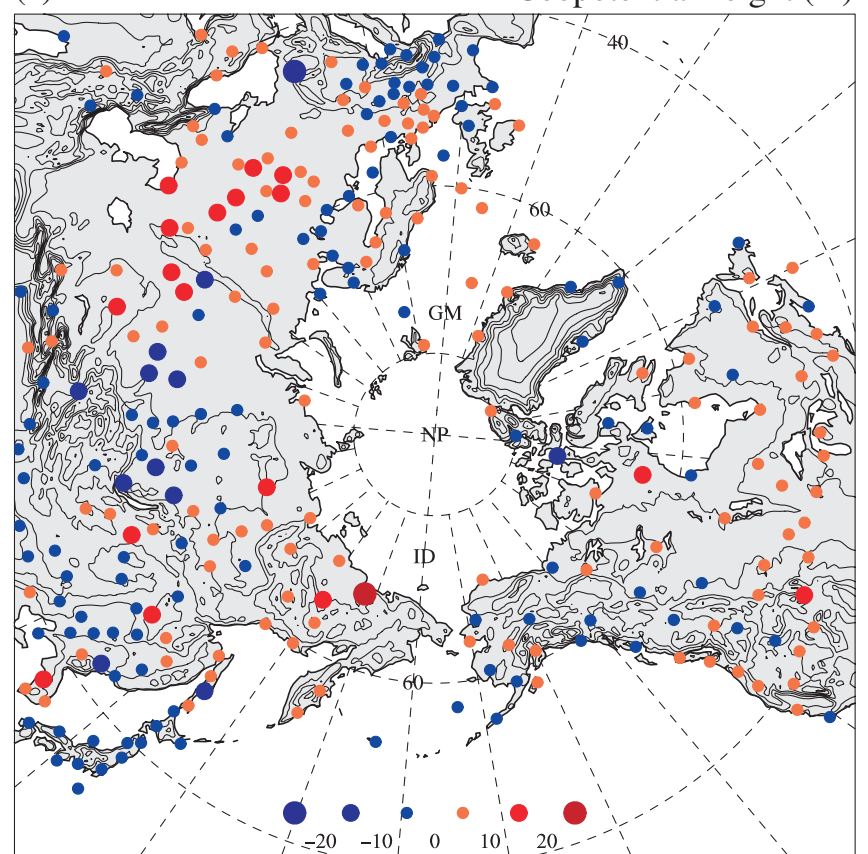

(b)

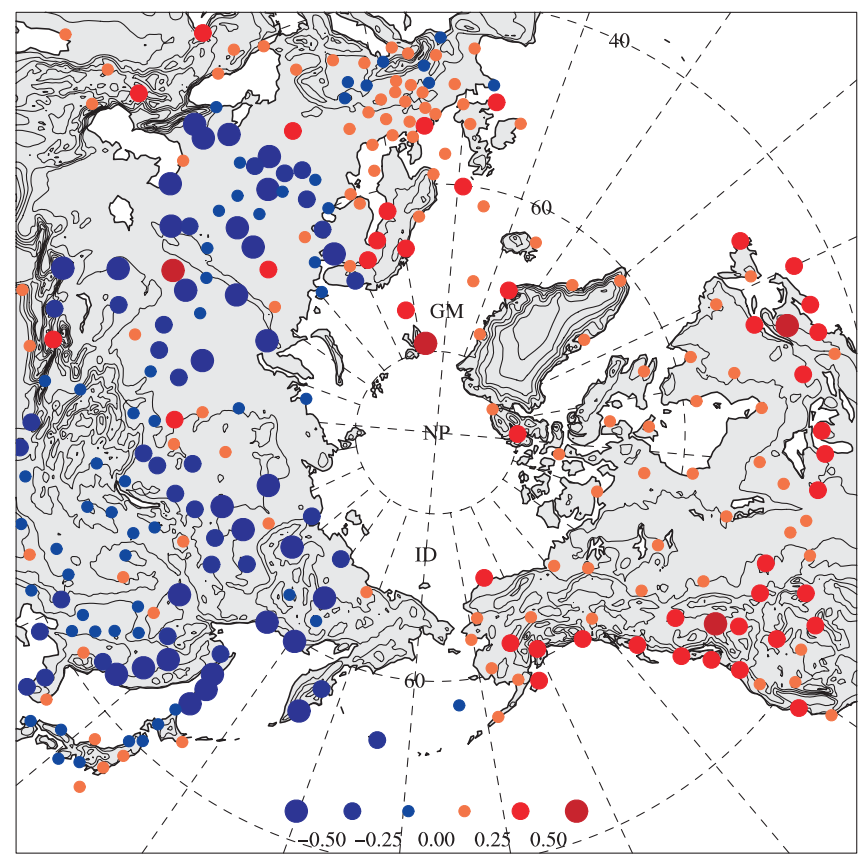

(d)

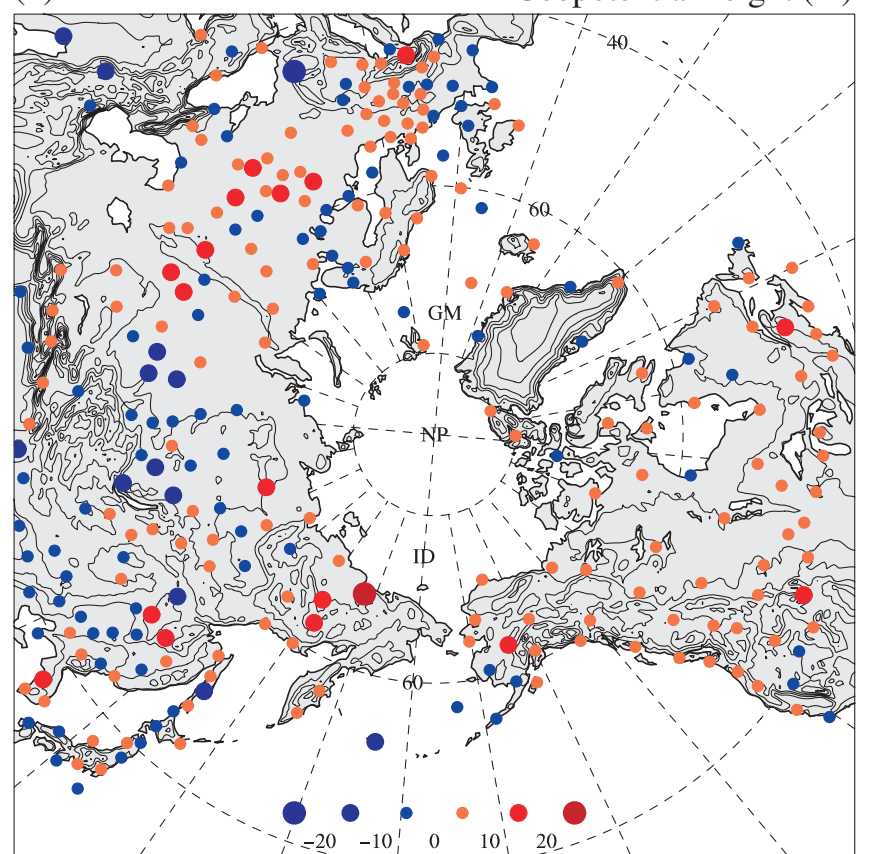

Figure 4. Annual mean biases for the period December 2006-November 2007 for the ASRv1 (a,c,e,g) and ERAI (b,d,f,h) for $(\mathrm{a}, \mathrm{b})$ temperature at $500 \mathrm{hPa}\left({ }^{\circ} \mathrm{C}\right),(\mathrm{c}, \mathrm{d})$ geopotential height at $500 \mathrm{hPa}(\mathrm{gpm}),(\mathrm{e}, \mathrm{f})$ relative humidity at $850 \mathrm{hPa}(\%)$ and $(\mathrm{g}, \mathrm{h})$ horizontal wind speed at $500 \mathrm{hPa}\left(\mathrm{m} \mathrm{s}^{-1}\right)$. Magnitudes of the biases are given by the colour scale and the size of the symbol.

while the non-convective component of precipitation that is dominant during winter is underpredicted.

In the Arctic, the ASRv1 demonstrates smaller biases on average than ERAI from September through February (Figure 5(c,f)), but generally is dry compared with observations (except January). The ERAI overestimates precipitation during September $(6.0 \%)$ and October (10.0\%), but similarly demonstrates negative biases during the other colder months. Except for July, the ASRv1 and ERAI underpredict precipitation during the warm months (not statistically different). The greatest of these biases in the ASRv1 occur during May, June and August, with biases of -22.8, -23.7 and $-17.2 \%$, respectively. So although precipitation in the Arctic during the cooler months is captured better by the ASRv1, summer precipitation forecasts in the ASRv1 are worse than ERAI. This implies a model issue with the moist physics used in the Polar WRF, with a general lack of low-level moisture over the Arctic during the summer (not shown).
In order to further quantify regional precipitation differences, Figure $6(a, b)$ shows the annual precipitation biases expressed as a percentage of the observed total for each station on the domain for the ASRv1 and ERAI, respectively. Annual biases are calculated as the difference between yearly totals (ASRv1/ERAI - observations). Both reanalyses show similar annual biases, with many midlatitude stations reflecting too much precipitation and a deficit in precipitation in the western Arctic region. In particular, the Canadian Archipelago shows large dry biases, which may demonstrate both the difficulty in precisely measuring precipitation in these locations as well as the fine-scale processes responsible for precipitation that are not entirely captured by even a regional reanalysis. Orographic lift and rain-shadow are also difficult precipitation processes to capture in complex terrain, demonstrated by the dry and wet biases in close proximity throughout the Rocky Mountains in the United States. Similar spatial results are found in a seasonal assessment of precipitation biases (not shown). 
(e)

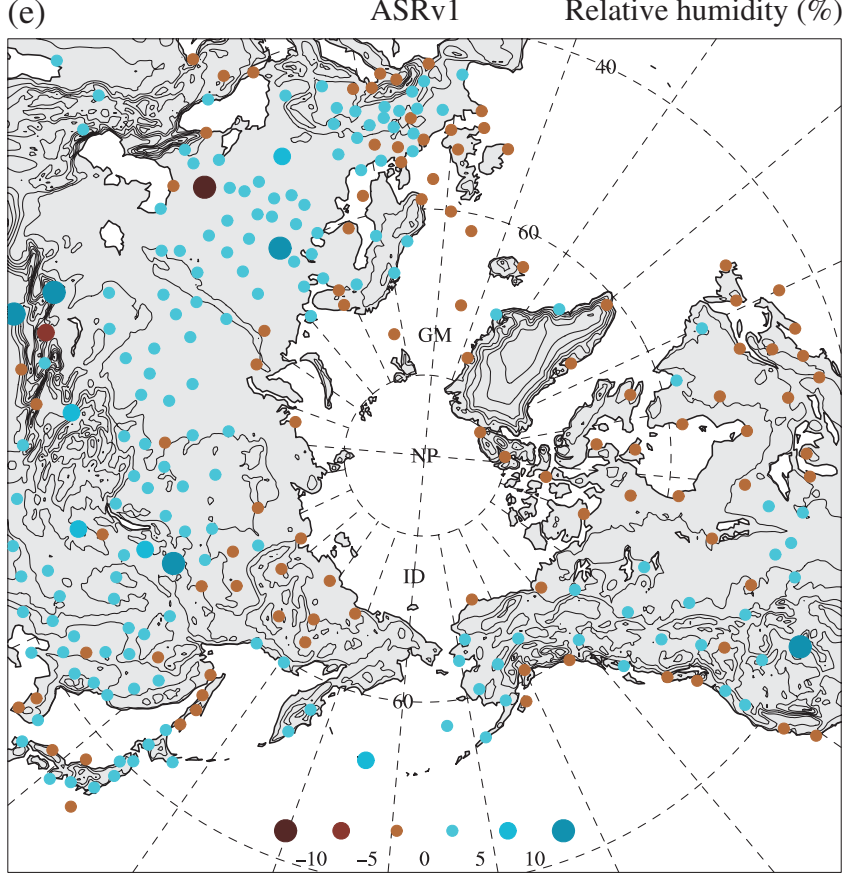

(g)

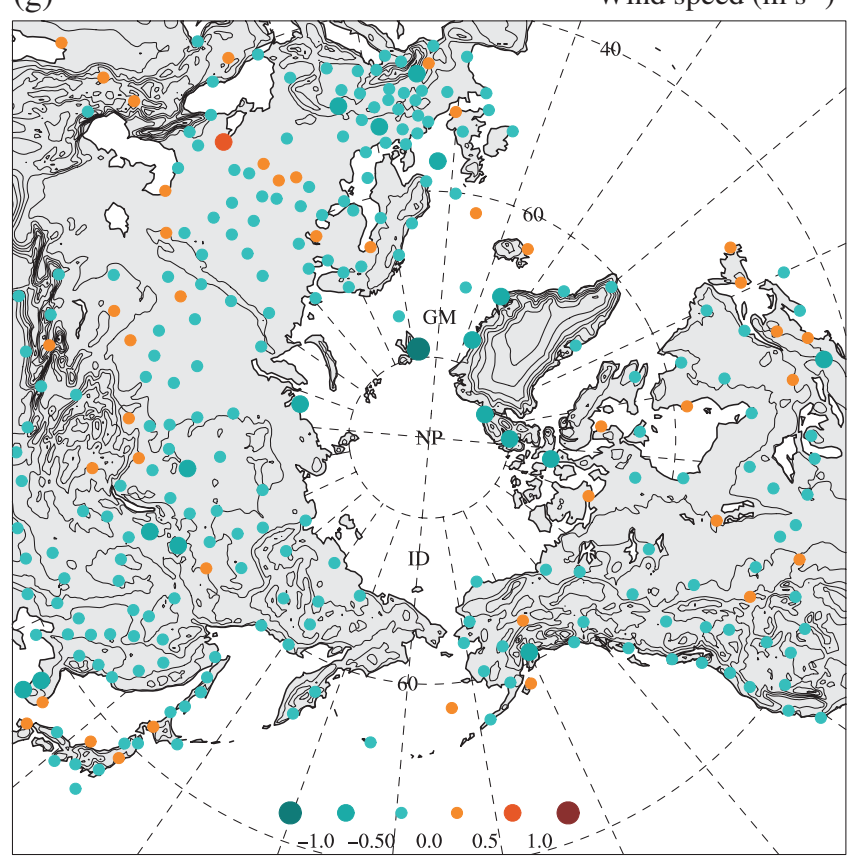

(f)

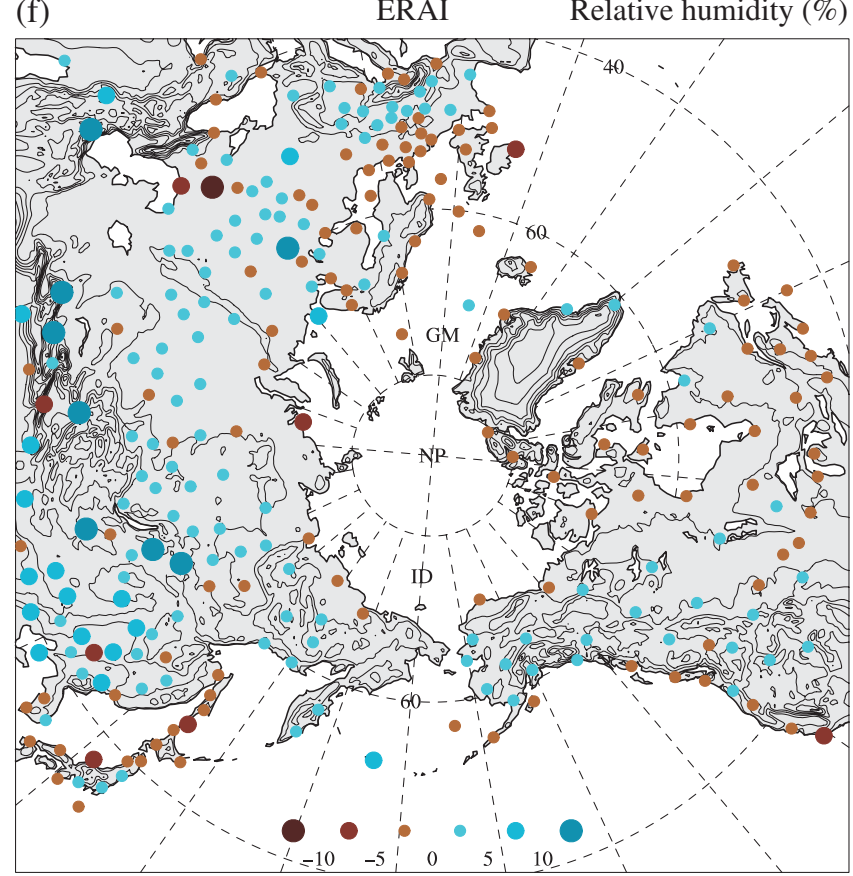

(h)

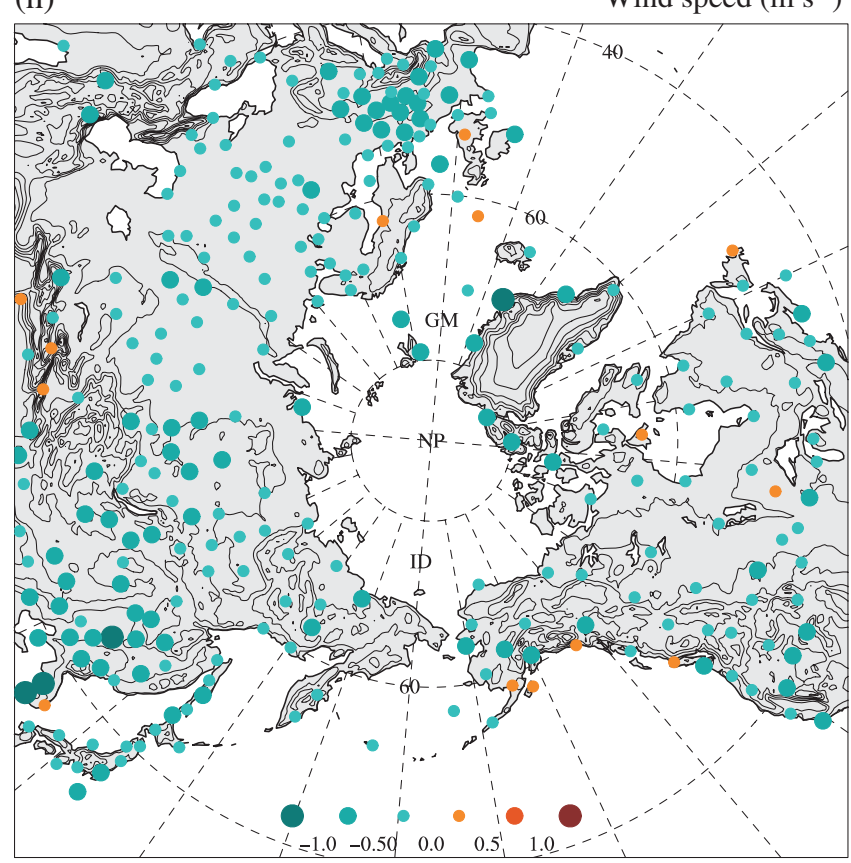

Figure 4. Continued.

The greatest difference between the ASRv1 and ERAI occurs during summer, when the ASRv1 precipitation biases compared with observations are much larger throughout the midlatitudes (polar region in July). The percentages of stations with significant annual biases compared with observations are calculated using the 12 -monthly values at each station. Compared with observations, the ASRv1 (21\%) has a greater percentage of stations with significant annual precipitation biases than the ERAI (4\%), with far more significant biases in the polar region. Overall, however, the mean annual biases for the ASRv1 and ERAI do not significantly differ in either subdomain, as shown by the confidence intervals in Figure 5(d)-(f).

Figure $6(\mathrm{c}, \mathrm{d})$ shows differences in their intensity distributions for January and July, respectively. These histograms show the number of occurrences that the daily precipitation rate falls within a particular category for all the stations in each region. For the polar region (blue) during January (Figure 6(c)), the number of dry days is much higher in the ERAI (357) than ASRv1 (2), however, very light precipitation $\left(<0.1 \mathrm{~mm} \mathrm{day}^{-1}\right)$ occurs more often in the ASRv1 than ERAI. For high precipitation rates, the ASRv1 and ERAI show similar results. Precipitation-rate differences are even greater in midlatitudes (green), as the ERAI has over 2000 occurrences of dry days while the ASRv1 has only 276. Again, the ASRv1 shows very light precipitation $\left(<0.1 \mathrm{~mm} \mathrm{day}^{-1}\right)$ on a large number of days (nearly 3500), much more than ERAI (963). Bollmeyer et al. (2015) used the German Meteorological Service's Consortium for Small-Scale Modelling (COSMO) to compare precipitation intensity distributions from over 1000 stations in Germany with the ERAI, and found that the ERAI underestimates the frequency of precipitation below $0.1 \mathrm{~mm} \mathrm{day}^{-1}$ and extremely heavy events $\left(>10.0 \mathrm{~mm} \mathrm{day}^{-1}\right)$. Indeed, the sum of all dry days and rates $<0.1 \mathrm{~mm} \mathrm{day}^{-1}$ in the ERAI in the midlatitudes (3229) is less than the ASRv1 (3704), but a direct comparison with observations is not possible here. It is probable that the ASRv1 is overproducing light precipitation $\left(<0.1 \mathrm{~mm} \mathrm{day}^{-1}\right)$, as this has been shown to occur with other regional simulations including the WRF (e.g., Caldwell et al., 2009; Soares et al., 2012). 
(a)

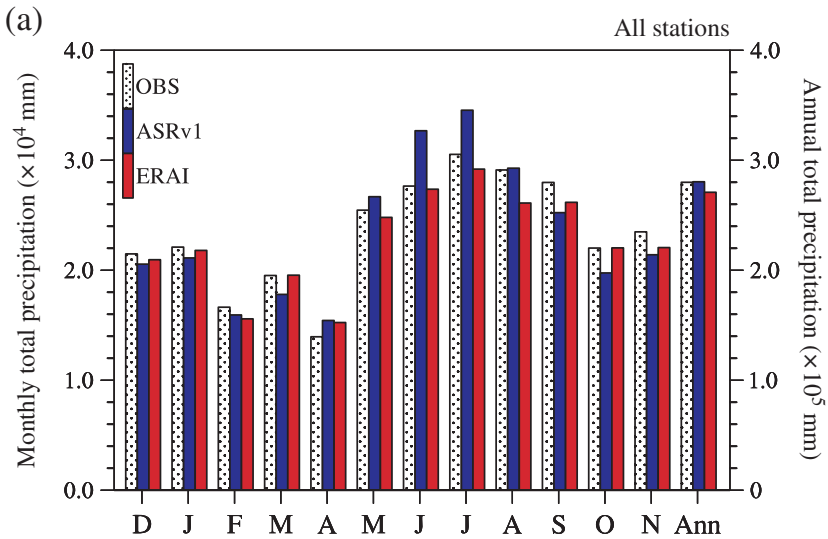

(b)

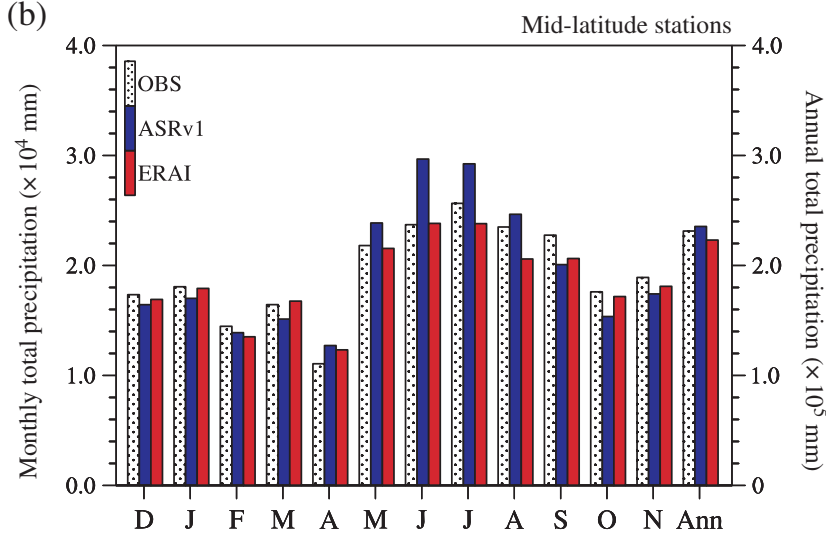

(c)

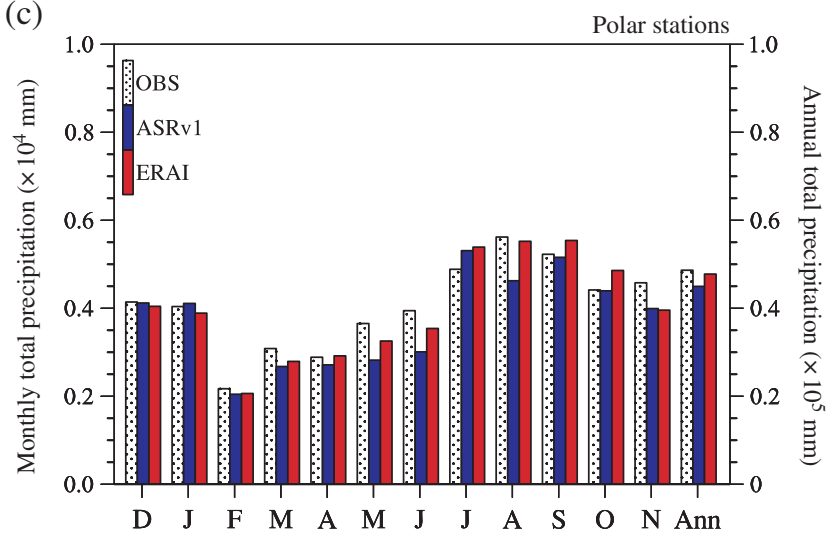

(d)

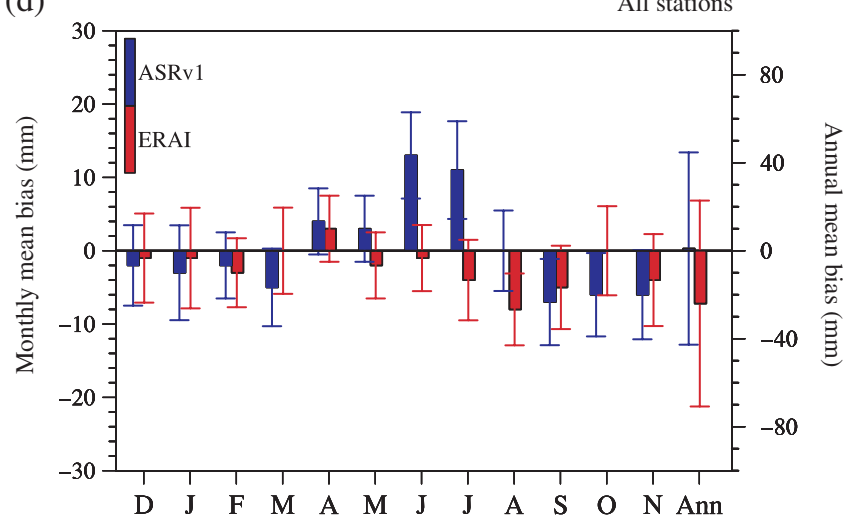

(e)

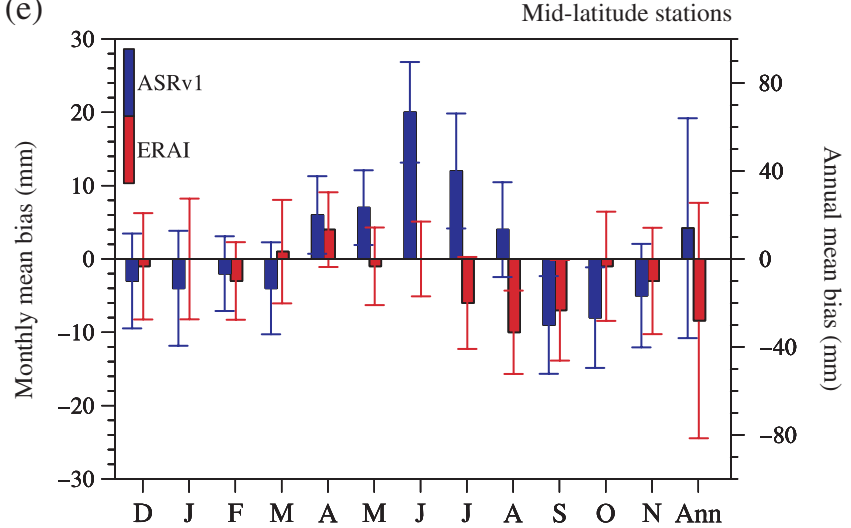

(f)

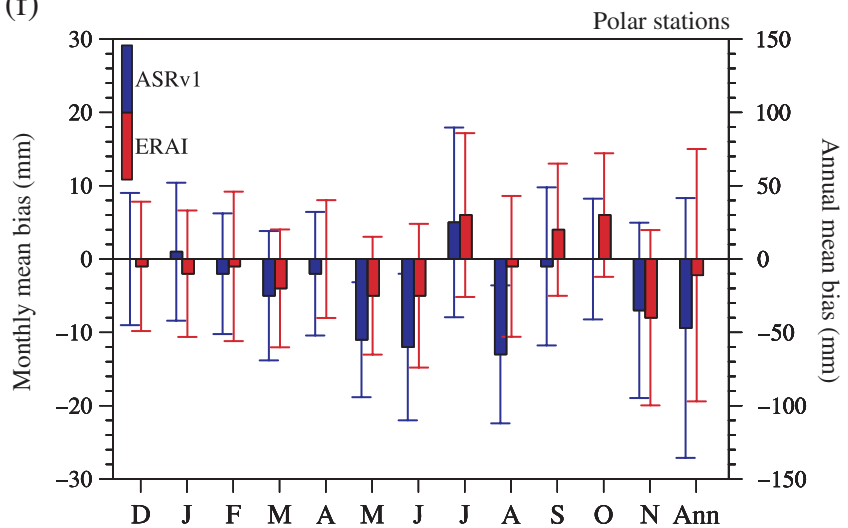

Figure 5. Monthly $\left(\times 10^{4} \mathrm{~mm}\right)$ and annual $\left(\times 10^{5} \mathrm{~mm}\right)$ precipitation (sum of stations) for the observed (dotted), ASRv1 (blue) and ERAI (red) for (a) all stations, (b) midlatitude stations and (c) polar stations. Station-mean monthly ( $\mathrm{mm}$ ) and annual precipitation biases (mm) are displayed for the ASRv1 (blue) and ERAI (red) for (d) all stations, (e) midlatitude stations and (f) polar stations. Error bars represent the $95 \%$ confidence intervals based on $\pm t_{95} \times$ SE for all the stations in each category. The left $y$-axis is for monthly biases and the right $y$-axis is for annual biases.

Overall, similar behaviour is displayed in Figure 6(d) for July, although more dry days occur during this month in the ASRv1 (closer agreement with the ERAI). For the higher precipitation rates $\left(>1.0 \mathrm{~mm} \mathrm{day}^{-1}\right)$, the ASRv1 is producing heavier rainfall, which is tied to the excessive convective precipitation during summer (Figure 5(b,e)). This is made further robust by the negative biases during winter when there is less convection, and large-scale precipitation dominates.

\subsection{Incident short-wave and downwelling long-wave radiation}

Radiation measurements from a number of sources have been used for this analysis, including Abisko, Sweden (http://www. linnea.com/ ans/), Atqasuk, Alaska (ARM; Ackerman and Stokes, 2003, Sodankylä, Finland (Climate Service Centre of the Finnish Meteorological Institute), Summit, Greenland (http://cires.colorado.edu/science/groups/steffen/gcnet/), and several stations from the World Climate Research Program Baseline Surface Radiation Network (Hegner et al., 1998;
Ohmura et al., 1998). For a full description of the data, see Wilson et al. (2012; cf. Figure 1 and Table 1). It should be noted that the limited selection of radiation sites means that these results should be interpreted more from a qualitative rather than domain-wide viewpoint when extrapolating the results to other areas of the domain.

Figures 7 and 8 show the mean biases, RMSEs and correlations for short-wave and long-wave radiation, respectively, along with the $95 \%$ confidence intervals of the means. Statistics are based on $3 \mathrm{~h}$ output, and as with precipitation, the stations are averaged over midlatitude and polar subregions. Mean biases for shortwave radiation at the surface for the ASRvl are positive in all months in the midlatitudes $\left(17.9-70.7 \mathrm{~W} \mathrm{~m}^{-2}\right.$ ) (Figure $7(\mathrm{a})$ ). The ERAI shows a much smaller bias in the midlatitudes, significantly lower than the ASRv1 in all months except August-October. The ASRv1 biases and RMSEs are quite large during the summer months (May-August), when the diurnal cycle is much more pronounced, and the summer biases are strongly reflected in the significant annual mean biases. Recall that over the midlatitudes, 
(a)
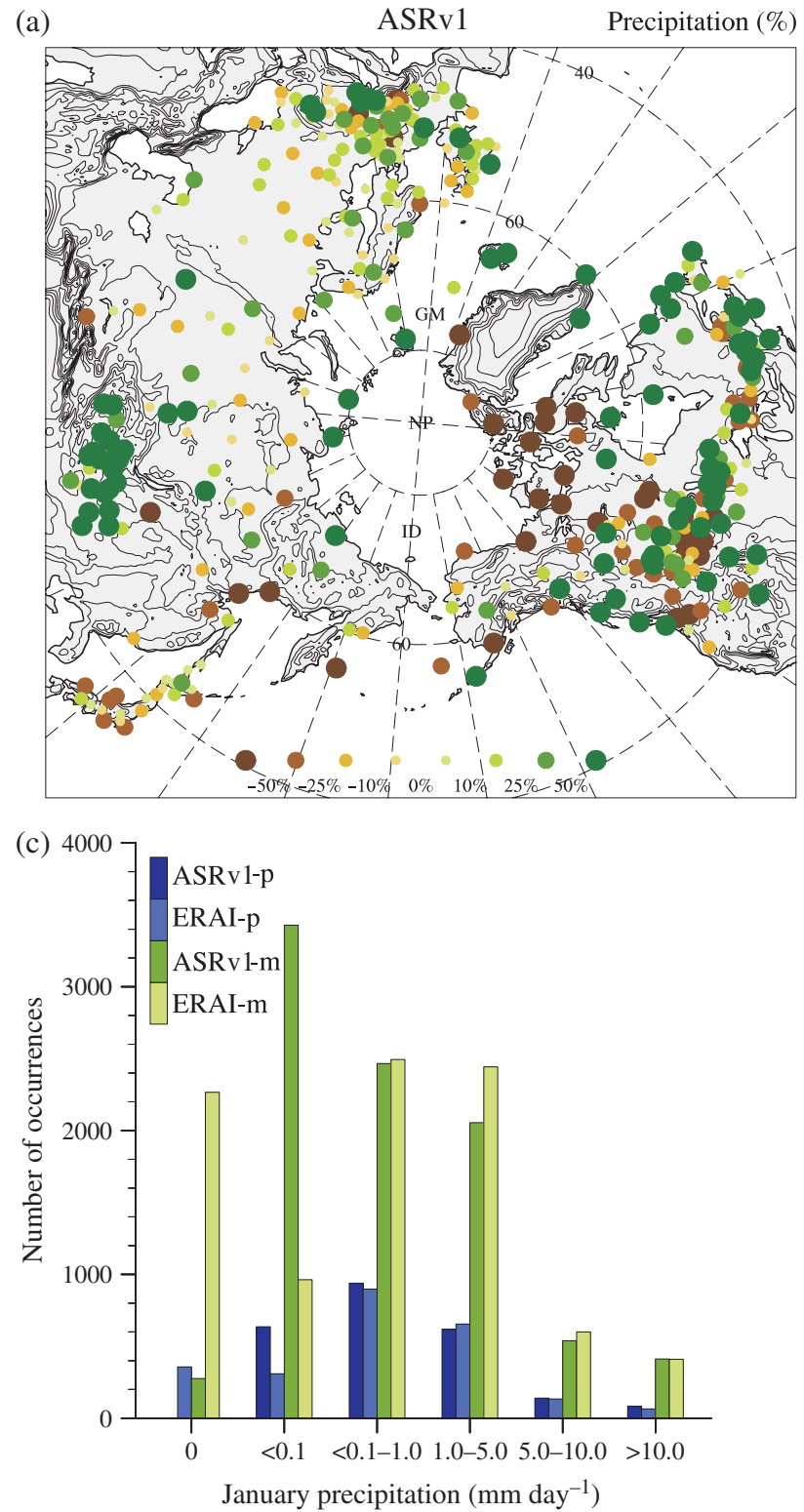

(b)

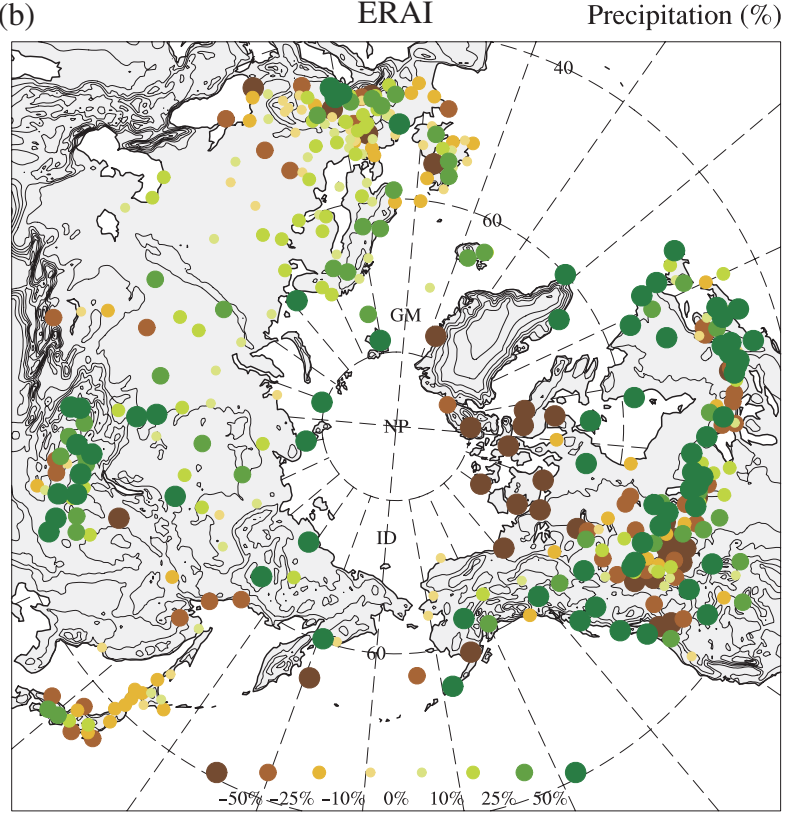

(d) 40007

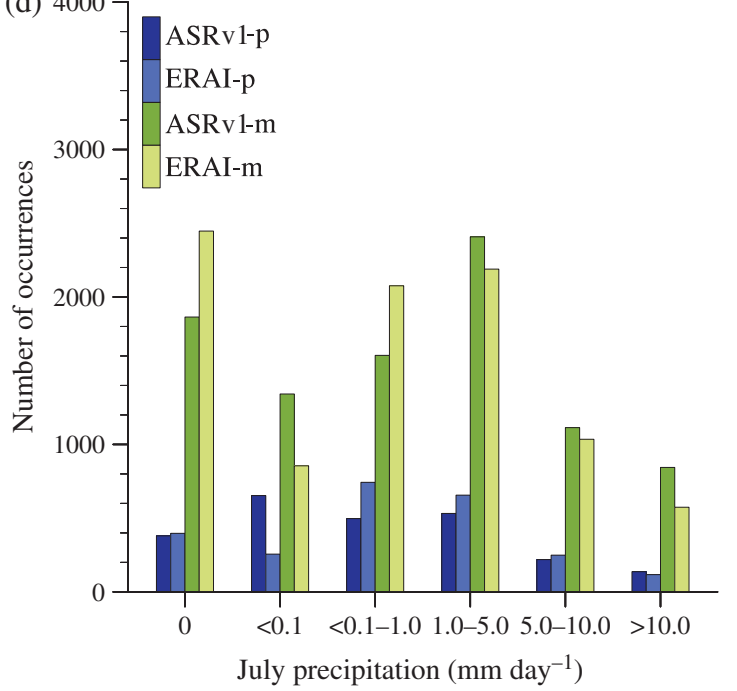

Figure 6. Annual mean precipitation biases (\%) for the period December 2006-November 2007 for the (a) ASRv1 and (b) ERAI. Magnitudes of the biases are given by the colour scale and the size of the symbol. (c,d) Histograms showing precipitation events in ASRv1 (dark) and ERAI (light) for specific thresholds in the polar (p; blue) and midlatitude ( $\mathrm{m}$; green) regions at the same locations used for the annual mean biases for January and July, respectively.

too much convective precipitation occurs during the summer months, while Figure 7(a) shows that summertime biases suggest too few clouds. In fact, continued WRF development has addressed this issue, as previous versions (like the version used for the ASRv1-Polar WRF 3.1.1) created convective precipitation but did not include convective cloud in the cloud fraction of the model. This physical inconsistency in the Polar WRF could not be overcome with data assimilation alone (Wesslén et al., 2014), but has been revised in the latest version of the Polar WRF used for the ASRv2 $15 \mathrm{~km}$.

For the polar stations (Figure 7(b)), the ASRv1 performs well during the colder months (October-March), although this is the time of year with minimal short-wave radiation in the Arctic. The magnitudes of the biases during this time are smaller than the ERAI (only significant in March), while RMSEs are lower and correlations are higher. Interestingly, the ERAI shows negative biases during most months in the Arctic, even throughout the summer when short-wave radiation is higher than observed in ASRv1 (1.4-46.7 $\mathrm{W} \mathrm{m}^{-2}$; Figure 7(b)). This further supports the conclusion that during the summer, differences in shortwave radiation are tied directly to radiative/cloud effects not fully captured by the model.

For the downwelling long-wave radiation in the midlatitudes (Figure $8(\mathrm{a})$ ), the ASRv1 biases are more negative than the
ERAI for all months except September, with biases in the ASRv1 from -8.8 to $-14.2 \mathrm{~W} \mathrm{~m}^{-2}$ and in the ERAI from -5.9 to $-10.9 \mathrm{~W} \mathrm{~m}^{-2}$. Although qualitatively this is physically consistent, as an excess of short-wave radiation can be compensated by a deficit in the downwelling long-wave radiation (total net incoming radiation), the magnitudes of the short-wave biases in the ASRv1 are much larger than for downwelling long-wave. Thus, the cloud properties (quantity and optical thickness) in the ASRv1 are suspect. Despite the lack of significant monthly differences between the ASRv1 and ERAI biases, their annual mean biases are statistically different. The ASRv1 midlatitude mean RMSEs and correlations also vary significantly with the ERAI, with better overall performance noted in the ERAI. For the polar region (Figure 8(b)), the ASRv1 again demonstrates negative long-wave radiation biases throughout all months except October $(-6.5$ to $\left.-23.6 \mathrm{~W} \mathrm{~m}^{-2}\right)$, with smaller biases in the ERAI $(-0.4$ to $-14.6 \mathrm{~W} \mathrm{~m}^{-2}$ ). However, there are no significant differences between ASRv1 and ERAI monthly biases, RMSEs or correlations.

\section{Conclusions}

Thus, we have demonstrated the ASR to be an important contribution to this generation of reanalyses, particularly in its depiction of the greater Arctic region. For the analysis results, 


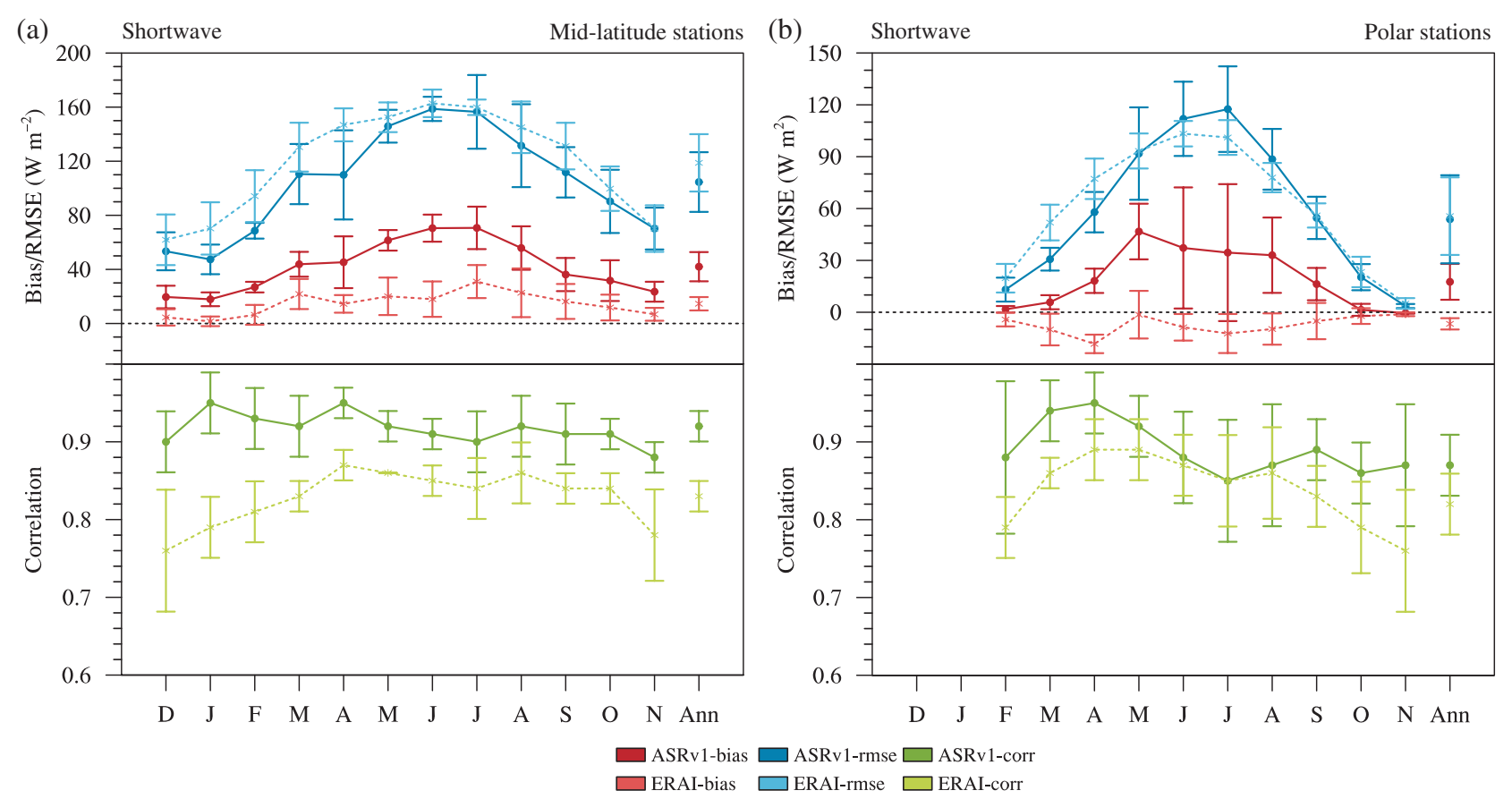

Figure 7. Station-mean monthly and annual short-wave radiation $\left(\mathrm{W} \mathrm{m}^{-2}\right.$ ) biases (red), RMSEs (blue) and correlations (green) for the ASRv1 (solid lines) and ERAI (dotted lines) for (a) midlatitude and (b) polar stations during the period December 2006-November 2007. Error bars represent the 95\% confidence intervals based on $\pm t_{95} \times$ SE of the biases, RMSEs and correlations for all the stations in each category. Confidence intervals for the annual means are based on the monthly mean biases, RMSEs, and correlations.

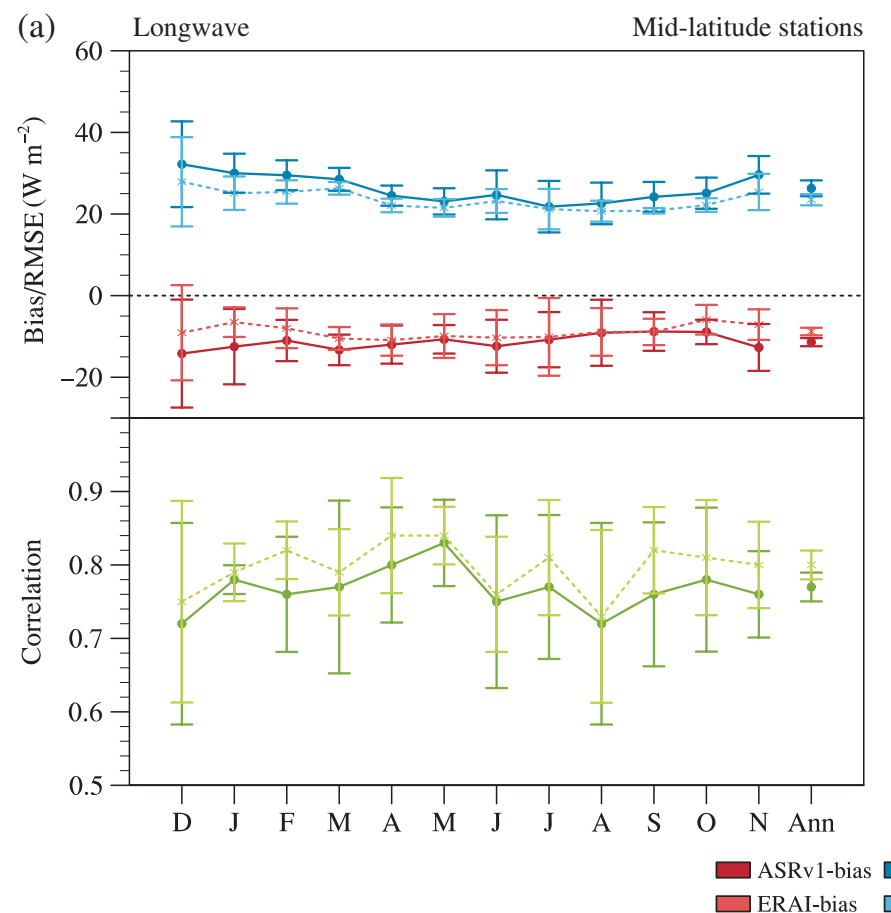

Figure 8. Same as Figure 7 except for downwelling long-wave radiation.

a comparison with observational data shows biases of $2 \mathrm{~m}$ temperature, $2 \mathrm{~m}$ dew-point, surface pressure and $10 \mathrm{~m}$ wind speeds that are comparable to the ERAI. The greatest advances in the ASRv1 over ERAI analysis fields are found in the near-surface moisture and wind fields. The RMSE and correlations improve in the ASRv1 for all variables, suggesting that the benefits lost between the 3D-Var assimilation used by the ASRv1 and the 4D-Var utilized by the ERAI are more than justified by the decrease in computational cost and the three-hourly cycling method used in the ASRv1. Even more encouraging, the upperlevel comparison with observations reveals smaller biases and RMSEs as well as higher correlations in the ASRv1 than in the ERAI, with distinct improvements in relative humidity and wind speed throughout the troposphere (Wesslén et al., 2014).

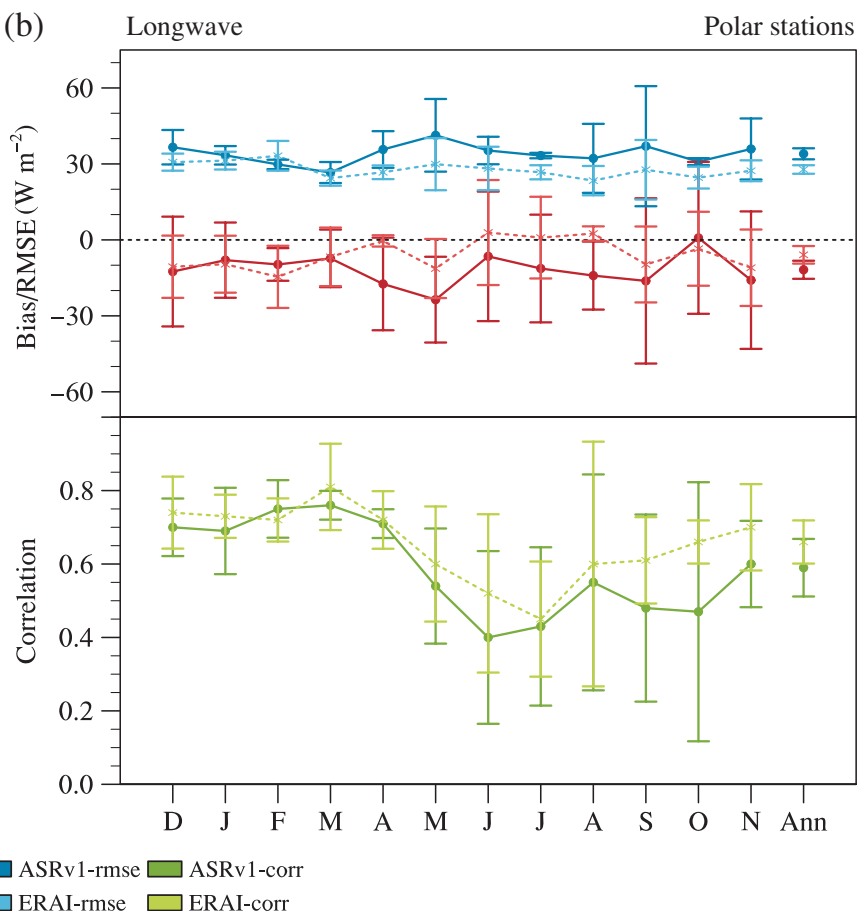

With the ASRv1 wind fields shown to be well represented, its strength lies in the depiction of mesoscale processes (studies forthcoming). The ASRv1 benefits from a regional assimilation of high-latitude observations and higher horizontal and vertical resolutions. Already the improvements in ASRv1 to the wind fields have proven beneficial for Arctic studies, including detailed depictions of processes responsible for wind events near Novaya Zemlya (Moore, 2013) as well as the life cycle, intensity, and regional development climatology of Arctic cyclones (Tilinina et al., 2014). This research demonstrates the potential for the ASR to provide important information regarding not only Arctic climate but also meteorological processes that are helpful for forecasting in this region. Certainly, a more detailed study beyond the scope of this current work is warranted, one featuring cyclone 


\section{H. Bromwich et al.}

tracking and analysis of mesoscale phenomena throughout the Arctic.

In general, the ASRv1 hydrologic forecast fields are not as accurate as the ERAI, and there are distinct model issues leading to large errors in the surface radiation. These forecast fields are intricately tied to the Polar WRF physics parametrizations, which have been shown to create excessive short-wave radiation and too much convective precipitation during summer (Wilson et al., 2012). Wesslén et al. (2014) demonstrated in an earlier version of the ASR that even with a sophisticated microphysics scheme, mixed-phase stratocumulus clouds during the ASCOS are not well captured. This has negative feedbacks on the surface energy budget and stability of the boundary layer. Not only are the representations of the moist processes different between the ASRv1 and ERAI, but the 4D-Var method in the ERAI leads to greater temporal consistency between the assimilated observations and the initialized state used to generate subsequent forecasts. With the ERAI, the ECMWF has also focused on improving the hydrological cycle through changes to the bias correction of radiance data.

This article, however, has resulted in a greater understanding of the strengths and needs that are still to be met for this Arctic reanalysis. The ASR version $2(15 \mathrm{~km})$ is currently being refined and will soon be made available. Along with higher horizontal resolution, key areas of development include changes to the Polar WRF moist physics that are expected to improve forecast fields of precipitation and radiation, and attention has been be given to the upper-level boundary near the top of the model (above $100 \mathrm{hPa}$ ). Additional sensitivity simulations may be performed in order to understand the impact of the non-hydrostatic versus hydrostatic formulations between the ASRv1 and ERAI, as well as their different mean states and resolutions. However, the ASR has already demonstrated its viability and significant contribution to the research community.

\section{Acknowledgements}

This work was supported by the National Science Foundation (NSF) through grants ARC-0733023 and ARC1144117. The authors thank the Ohio SuperComputer Center (http://www.osc.edu) for their use of the Glenn and Oakley Clusters in order to conduct the ASR. The authors also thank the Natural Sciences and Engineering Research Council of Canada, as well as two anonymous reviewers for their helpful comments.

\section{References}

Accadia C, Mariani S, Casaioli M, Lavagnini A, Speranza A. 2003. Sensitivity of precipitation forecast skill scores to bilinear interpolation and a simple nearest-neighbor average method on high-resolution verification grids. Weather and Forecasting 118: 918-932.

Ackerman T, Stokes G. 2003. The atmospheric radiation measurement program. Phys. Today 56: 38-45.

Bamber JL, Ekholm S, Krabill WB. 2001. A new, high-resolution digital elevation model of Greenland fully validated with airborne laser altimeter data. J. Geophys. Res. 106: 6733-6745, doi: 10.1029/2000JB900365.

Barker DM, Huang W, Guo Y-R, Bourgeois AJ, Xiao QN. 2004. A threedimensional (3DVAR) data assimilation system for use with MM5: Implementation and initial results. Mon. Weather Rev. 132: 897-914.

Bechtold P, Köhler M, Jung T, Doblas-Reyes F, Luetbecher M, Rodwell MJ, Vitart F, Balsamo G. 2008. Advances in simulating atmospheric variability with the ECMWF model: From synoptic to decadal time scales. Q. J. R. Meteorol. Soc. 134: 1337-1351, doi: 10.1002/qj.289.

Bengtsson L, Arkin P, Berrisford P, Bougeault P, Folland CK, Gordon C, Haines K, Hodges KI, Jones P, Kållberg P, Rayner N, Simmons AJ, Stammer D, Thorne PW, Uppala S, Vose RS. 2007. The need for a dynamical climate reanalysis. Bull. Am. Meteorol. Soc. 88: 495-501.

Bollmeyer C, Keller JD, Ohlwein C, Wahl S, Crewell S, Friederichs P, Hense A, Keune J, Kneifel S, Pscheidt I, Redl S, Steinke S. 2015. Towards a highresolution regional reanalysis for the European CORDEX domain. Q. J. R. Meteorol. Soc. 141: 1-15, doi: 10.1002/qj.2486.

Bromwich DH, Hines KM, Bai L-S. 2009. Development and testing of Polar WRF: 2. Arctic Ocean. J. Geophys. Res. 114: D08122, doi: 10.1029/ 2008JD010300.
Bromwich DH, Kuo Y-H, Serreze M, Walsh J, Bai L-S, Barlage M, Hines KM, Slater A. 2010. Arctic system reanalysis: Call for community involvement. Eos Trans. Am. Geophys. Union 91: 13-14.

Caldwell P, Chin H-NS, Bader DC, Bala G. 2009. Evaluation of a WRF dynamical downscaling simulation over California. Clim. Change 95: 499-521.

Chen F, Dudhia J. 2001. Coupling an advanced land surface-hydrology model with the Penn State-NCAR MM5 modeling system. Part I. Model and implementation and sensitivity. Mon. Weather Rev. 129: 569-585.

Chen F, Manning KW, LeMone MA, Trier SB, Alfieri JG, Roberts R, Tewari M, Niyogi D, Horst TW, Oncley SP, Basara JB, Blanken PD. 2007. Description and evaluation of the characteristics of the NCAR high-resolution land data assimilation system. J. Appl. Meteorol. Climatol. 46: 694-713, doi: 10.1175/JAM2463.1.

Dee DP, Uppala SM, Simmons AJ, Berrisford P, Poli P, Kobayashi S, Andrae U, Balmaseda MA, Blasamo G, Bauer P, Bechtold P, Beljaars ACM, Van De Berg L, Bidlot J, Bormann N, Delsol C, Dragani R, Fuentes M, Geer AJ, Haimberger L, Healy SB, Hersbach H, Hólm EV, Isaksen L, Kållberg P, Köhler M, Matricardi M, McNally AP, Monge-Sanz BM, Morcrette JJ, Park B-K, Peubey C, De Rosnay P, Tavolato C, Thépaut J-N, Vitart F. 2011. The ERA-Interim reanalysis: Configuration and performance of the data assimilation system. Q. J. R. Meteorol. Soc. 37: 553-597, doi: 10.1002/qj.828.

Dee DP, Balmaseda M, Balsamo G, Engelen R, Simmons AJ, Thépaut J-N. 2014. Toward a consistent reanalysis of the climate system. Bull. Am. Meteorol. Soc. 95: 1235-1248, doi: 10.1175/BAMS-D-13-00043.1.

Devine KA, Mekis È. 2008. Field accuracy of Canadian rain measurements. Atmos. Ocean 46: 213-227.

Durre I, Yin X. 2008. Enhanced radiosonde data for studies of vertical structure. Bull. Am. Meteorol. Soc. 89: 1257-1262, doi: 10.1175/2008BAMS2603.1.

Easterling DR, Peterson TC. 1995. A new method for detecting undocumented discontinuities in climatological time series. Int. J. Climatol. 15: 369-377.

Ekholm S. 1996. A full coverage high-resolution topographic model of Greenland computed from a variety of digital elevation data. J. Geophys. Res. 101: 21961-21972, doi: 10.1029/96JB01912.

Fisher M. 2003. Background-error covariance modelling. Proceedings of Seminar on Recent Developments in Data Assimilation for Atmosphere and Ocean, 8-12 September 2003. ECMWF: Reading, UK, 45-63.

Fisher M, Courtier P. 1995. Estimating the Covariance Matrices of Analysis and Forecast Error in Variational Data Assimilation, Technical Memorandum No. 220. ECMF: Reading, UK.

Hegner H, Müller G, Nespor V, Ohmura A, Steigrad R, Gilgen H. 1998. 'World Climate Research Program WCRP (WMO/ICSU/IOC) Baseline Surface Radiation Network (BSRN): Update of the technical plan for BSRN data management', Version 1.0. Technical report 2. World Radiation Monitoring Center (WRMC), Institute of Geography ETH: Zurich, Switzerland.

Hines KM, Bromwich DH. 2008. Development and testing of Polar WRF. Part I: Greenland ice sheet meteorology. Mon. Weather Rev. 136: 1971-1989, doi: 10.1175/2007MWR2112.1.

Hines KM, Bromwich DH, Bai L-S, Barlage M, Slater AG. 2011. Development and testing of Polar WRF: Part III. Arctic Land. J. Clim. 24: 26-48, doi: 10.1175/2010JCLI3460.1.

Hofstra N, New M, McSweeny C. 2010. The influence of interpolation and station network density on the distributions and trends of climate variables in gridded daily data. Clim. Dyn. 35: 841-858, doi: 10.1007/s00382-0090698-1.

Hong S-Y, Kanamitsu M. 2014. Dynamical downscaling: Fundamental issues from an NWP point of view and recommendations. Asia-Pac. J. Atmos. Sci. 50: 83-104, doi: 10.1007/s13143-014-0029-2.

Iacono MJ, Delamere JS, Mlawer EJ, Shephard MW, Clough SA, Collins WD. 2008. Radiative forcing by long-lived greenhouse gases: Calculations with AER radiative transfer models. J. Geophys. Res. 113: D13103, doi: 10.1029/2008JD009944.

Jung T, Balsamo G, Bechtold P, Beljaars ACM, Köhler M, Miller MJ, Morcrette J-J, Orr A, Rodwell MJ, Tompkins AM. 2010. The ECMWF model climate: Recent progress through improved physical parameterizations. Q. J. R. Meteorol. Soc. 136: 1145-1160, doi: 10.1002/qj.634.

Kain JS. 2004. The Kain-Fritsch convective parameterization: An update. J. Appl. Meteorol. 43: 170-181.

Kain JS, Fritsch JM. 1990. A one-dimensional entraining/detraining plume model and its application in convective parameterization. J. Atmos. Sci. 47: 2784-2802.

Kain JS, Fritsch JM. 1993. Convective parameterization for mesoscale models: The Kain-Fritsch scheme. In The Representation of Cumulus Convection in Numerical Models, Emanuel KA, Raymond DJ. (eds.): 246 pp. American Meteorological Society: Boston, MA.

Laprise R. 2008. Regional climate modeling. J. Comput. Phys. 227: 3641-3666, doi: 10.1016/j.jcp.2006.10.024.

McGregor JL. 2013. Recent developments in variable-resolution global climate modelling. Clim. Change, doi: 10.1007/s10584-013-0866-5.

Mekis È. 2005. Adjustments for trace measurements in Canada. Proceedings of the 15th Conference on Applied Climatology, 20-24 Jun 2005. Savannah, GA. American Meteorological Society: Boston, MA.

Mekis È, Hogg WD. 1999. Rehabilitation and analysis of Canadian daily precipitation time series. Atmos. Ocean 37: 53-85.

Mekis È, Hopkinson R. 2004. 'Derivation of an improved snow water equivalent adjustment factor map for application on snowfall ruler measurements in 
Canada'. In Proceedings of the 14th Conference on Applied Climatology, 12-15 January 2004. Seattle, WA. American Meteorological Society: Boston, MA $12-15$.

Mlawer EJ, Taubman SJ, Brown PD, Iacono MJ, Clough SA. 1997. Radiative transfer for inhomogeneous atmosphere: RRTM, a validated correlated-k model for the longwave. J. Geophys. Res. 102: D14, doi: 10.1029/97JD00237.

Moore GWK. 2012. A new look at Greenland flow distortion and its impact on barrier flow, tip jets and coastal oceanography. Geophys. Res. Lett. 39 L22806, doi: 10.1029/2012GL054017.

Moore GWK. 2013. The Novaya Zemlya bora and its impact on the Barrents Sea air-sea interaction. Geophys. Res. Lett. 40: 3462-3467, doi 10.1002/grl.50641.

Moore GWK, Renfrew IA. 2014. A new look at Southeast Greenland barrier winds and katabatic flow. US CLIVAR Variations Newsl. 12: 13-19.

Moore GWK, Renfrew IA, Cassano JJ. 2013. Greenland plateau jets. Tellus A 65: 17468 , doi: $10.3402 /$ tellusa.v65i0.17468

Nakanishi M. 2001. Improvement of the Mellor-Yamada turbulence closure model based on large-eddy simulation data. Boundary Layer Meteorol. 99 349-378.

Nakanishi M, Niino H. 2004. An improved Mellor-Yamada level-3 model with condensation physics: Its design and verification. Boundary Layer Meteorol. 112: $1-31$

Nakanishi M, Niino H. 2006. An improved Mellor-Yamada level3 model. Its numerical stability and application to a regional prediction of advection fog. Boundary Layer Meteorol. 119: 397-407.

Ohmura A, Gilgen H, Hegner H, Müller G, Wild M, Dutton EG, Forgan B, Fröhlich C, Philipona C, Heimo A, König-Langlo G, McArthur B, Pinke R, Whitlock CH, Dehne K. 1998. Baseline Surface Radiation Network (BSRN/WCRP): New precision radiometry for climate research. Bull. Am. Meteorol. Soc. 79: 2115-2136.

Oltmanns M, Straneo F, Moore GWK, Mernild SH. 2014. Strong downslope wind events in Ammassalik, Southeast Greenland. J. Clim. 27: 977-993.

Peterson TC, Easterling DR. 1994. Creation of homogeneous composite climatological reference series. Int. J. Climatol. 14: 671-679.

Peterson TC, Vose RS. 1997. An overview of the Global Historical Climatology Network temperature database. Bull. Am. Meteorol. Soc. 78: 2837-2849.

Renfrew IA, Petersen GN, Outten S, Sproson D, Moore GWK, Hay C, Ohigashi T, Zhang S, Kristjansson JE, Fore I, Olafsson H, Gray SL, Irvine EA Bovis K, Brown PRA, Swinback R, Haine T, Lawrence A, Pickart RS, Shapiro M, Woolley A. 2008. The Greeland flow distortion experiment Bull. Am. Meteorol. Soc. 89: 1307-1324, doi: 10.1175/2008BAMS2508.1.

Rienecker MM, Suarez MJ, Gelaro R, Todling R, Bacmeister J, Liu E, Bosilovich MG, Schubert SD, Takacs L, Kim G-K, Bloom S, Chen J, Collins D, Conaty A, da Silva A, Gu W, Joiner J, Koster RD, Lucchesi R, Molod A, Owens T, Pawson S, Pegion P, Redder CR, Reichle R, Robertson FR, Ruddick AG, Sienkiewicz M, Woollen J. 2011. MERRA: NASA's modern-era retrospective analysis for research and application. J. Clim. 24: 3624-3648, doi: 10.1175/JCLI-D-11-00015.1.

Saha S, Moorthi S, Pan H-L, Wu X, Wang J, Nadiga S, Tripp P, Kistler R, Woollen J, Behringer D, Liu H, Stokes D, Grumbine R, Gayno H, Wang J, Hou Y-T, Chuang H-Y, Juang H-MH, Sela J, Iredell M, Treadon R, Kleist D Delst PV, Keyser D, Derber J, Ek M, Meng J, Wei H, Yang R, Lord S, van den Dool H, Kumar A, Wang W, Long C, Chelliah M, Zhou S, Higgins W, Zou C-Z, Liu Q, Chen Y, Han Y, Cucurull L, Reynolds RW, Rutledge G Goldberg M. 2010. The NCEP climate forecast system reanalysis. Bull. Am. Meteorol. Soc. 91: 1015-1057.
Schweiger A, Lindsay R, Zhang J, Steele M, Stern H. 2011. Uncertainty in modeled Arctic sea ice volume. I. Geophys. Res. 116: C00D06, doi: 10.1029/ 2011JC007084.

Simmons AJ, Willett KM, Jones PD, Thorne PW, Dee DP. 2010. Lowfrequency variations in surface atmospheric humidity, temperature, and precipitation: Inferences from reanalyses and monthly gridded observational data set. J. Geophys. Res. 115: D01110, doi: 10.1029/2009 JD012442.

Skamarock WC, Klemp JB, Dudhia J, Gill D, Barker D, Dudhia M, Huang X-Y, Wang W, Powers JG. 2008. 'A description of the advanced research WRF version 3', Technical Note TN-475+STR. NCAR: Boulder, CO.

Soares PMM, Cadoso RM, Miranda PMA, Viterbo P, Belo-Pereira M 2012. Assessment of the ENSEMBLES regional climate models in the representation of precipitation variability and extremes over Portugal. J. Geophys. Res. 117: D07114, doi: 10.1029/2011JD016768.

von Storch H, Lagenberg H, Feser F. 2000. A spectral nudging technique for dynamical downscaling purposes. Mon. Weather Rev. 128 3664-3673.

Tao W-K, Simpson J. 1993. The Goddard Cumulus Ensemble model. Part I. Model description. Terr. Atmos. Ocean. Sci. 4: 19-54.

Tao W-K, Simpson J, Baker D, Chou M-D, Ferrier B, Johnson D, Khain A, Lang S, Lynn B, Shie C-L, Starr D, Sui C-H, Wang Y, Wetzel P. 2003. Microphysics, radiation and surface processes in the Goddard Cumulus Ensemble (GCE) model. Meteorol. Atmos. Phys. 82: 97-137.

Tilinina N, Gulev SK, Bromwich DH. 2014. New view of Arctic cyclone activity from the Arctic system reanalysis. Geophys. Res. Lett. 41: 1766-1772, doi: 10.1002/2013GL058924.

Uppala SM, Kållberg PW, Simmons AJ, Andrae U, Da Cost Bechtold V, Fiorino M, Gibson JK, Haseler J, Hernandez A, Kelly GA, Li X, Onogi K, Saarinen S, Sokka N, Allan RP, Andersson E, Arpe K, Balmaseda KM, Beljaars ACM, Van De Berg L, Bidlot J, Bormann N, Caires S, Chevallier F, Dethof D, Dragosavac M, Fisher M, Fuentes M, Hagemann S, Hólm E, Hoskins BJ, Isaksen L, Janssen PAEM, Jenne R, McNally AP, Mahfouf J-F, Morcrette J-J, Rayner NA, Saunders RW, Simon P, Sterl A, Trenberth KE, Untch A, Vasiljevic D, Viterbo P, Woollen J. 2005. The ERA-40 re-analysis. Q. J. R. Meteorol. Soc. 131: 2961-3012, doi: 10.1256/qj.04.176.

Waldon KM, Paegle J, Horel JD. 1996. Sensitivity of a spectrally filtered and nudged limited area model to outer model options. Mon. Weather Rev. 124 529-547.

Wang Y, Leung LR, McGregor JL, Lee D-K, Wang W-C, Ding Y, Kimura F. 2004 Regional climate modeling: Progress, challenges, and prospects. J. Meteorol. Soc. Jpn. 82: 1599-1628.

Wesslén C, Tjernström M, Bromwich DH, de Boer G, Ekman AML, Bai L-S, Wang S-H. 2014. The Arctic summer atmosphere: An evaluation of reanalyses using ASCOS data. Atmos. Chem. Phys. Discuss. 13: 16495-16547, doi: 10.5194/acpd-13-16495-2013.

Wilson AB, Bromwich DH, Hines KM. 2011. Evaluation of Polar WRF forecasts on the Arctic System domain: Surface and upper air analysis. J. Geophys. Res. 116: D11112, doi: 10.1029/2010JD015013.

Wilson AB, Bromwich DH, Hines KM. 2012. Evaluation of Polar WRF forecasts on the Arctic System Reanalysis domain. 2. Atmospheric hydrologic cycle. J. Geophys. Res. 17: D04107, DOI: 10.1029/2011JD016765.

Wolff JK, Harrold M, Fowler T, Halley J, Gotway LN, Brown BG. 2014. Beyond the basics: Evaluating model-based precipitation forecasts using traditional, spatial, and object-based methods. Weather and Forecasting 29: 1451-1472, doi: 10.1175/WAF-D-13-00135.1. 